\title{
5 Undeserved Trust: Reflections on the ALI's Treatment of De Facto Parents
}

\author{
Robin Fretwell Wilson
}

In chapter 2 of the PRINCIPLES, the ALI proposes sweeping changes to the legal conception of parenthood. It would confer custody and visitation "rights"1 on a stepparent or ex-livein lover of a child's legal parent ${ }^{2}$ who shared caretaking responsibility for a child for as little as two years ("Ex Live-In Partner"). ${ }^{3}$ Such an individual is recognized by the Principles as a "de facto parent," a term the Principles borrow from case law. The Principles would significantly enlarge the rights these individuals receive under state law, however. With the same stroke, the ALI would dispossess legal parents of the prerogative to decide who continues to have contact with their child. ${ }^{4}$

In many ways, the ALI is engaged in an admirable undertaking: to provide children with enduring contact with the "only father [a] child ha[d] known." But like much of our experience with "re-imagining" family relations, significant unintended consequences

\footnotetext{
${ }^{1}$ Principles ch. 1, Topic 1.I (d), at 5-6.

2 This chapter uses legal parent, as the Principles do, to mean biological parents and adoptive parents. See PrinCIPLES $₫ 2.03 \mathrm{cmt}$. a, at 110 .

There are good reasons that legal parents have a constitutionally protected status. PRINCIPLES $\$ 2.18$, Reporter's Notes, cmt. b, at 389-90 (discussing natural parents). "[T]he autonomy of parents... is essential to their meaningful exercise of responsibility." Principles ch. 1, Topic 1.I (d), at 5-6. Moreover, legal parents exhibit "maximum commitment to the parenting enterprise." Principles ch. 1, Topic 1.I (d), at 5. This observation is grounded in a substantial body of social science. Part III.C infra discusses how the presence of one's mother is protective of children, while separation from one or both biological parents introduces risk. In the same vein, numerous studies find that adoptive parents invest in their children as heavily, or more heavily, than do biological parents. See generally Robin Fretwell Wilson, Uncovering the Rationale for Requiring Infertility in Surrogacy Arrangements, 29 Aм. J. L. \& MED. 337 (2003). Unlike other nongenetic caretakers, such as foster parents, stepparents, and mothers' cohabitants, there is little evidence that adoptive parents engage in more neglect or abuse of their children. Id.

${ }^{3}$ This chapter uses the term "Ex Live-In Partner" to describe the population of male "de facto parents" on whom the ALI would confer significantly expanded parental rights. The common denominator among this group of men is their previous status as coresidents of the child's mother, together with their performance of certain "caretaking functions." See Principles $\$ 2.03(\mathrm{c})$. As this chapter argues throughout, we cannot infer from the fact that these men have performed "caretaking functions" that they necessarily have undertaken to assume a level of care, permanency, and bonding in a child's life that warrants recognition and treatment as a parent. Performance of "caretaking" chores, this chapter argues, does little to discern how protective these men have been or will be. See Part IV infra. Moreover, the fact that they are unrelated is relevant to the risks posed to children with whom they may have continuing contact, see Part II.A. infra, as well as to the degree of benefit that continuing contact may hold for children, see Parts II.B. \& III.E. infra.

${ }^{4}$ The drafters are candid about the ALI's proposal. They acknowledge that courts have used equitable doctrines, like estoppel, to extend "parental rights to an individual who otherwise would not qualify." PRINCIPLES $\$ 2.03$, Reporter's Notes, cmt. b, at 128. Like those equitable doctrines, the drafters seek to confer custody and visitation rights "over the opposition of the legal parent." Principles $\$ 2.03$, Reporter's Notes, cmt. b, at 129.

${ }^{5}$ See Principles $\$ 2.03 \mathrm{cmt}$. b, at 129 (discussing equitable-parent cases).
} 
may result. ${ }^{6}$ The drafters, without substantiation, simply assume that continuing contact between a child and an Ex Live-In Partner - who will almost always be male ${ }^{7}$ - will be an unadulterated good.

The story they tell reads like this: Giving parental rights to a "de facto parent" is necessary to conform to the lived experience of many children, who are "often cared for by adults other than parents[, such as] stepparents... and parental partners who function as coparents." Continued contact with a de facto parent and his participation in the child's life, they explain, are "critically important to the child's welfare." This is so because the de facto parent functioned as the child's primary parent or undertook equal caretaking duties. ${ }^{10}$ Disregarding the connection between a child and this adult at break-up, they tell us, "ignores child-parent relationships that may be fundamental to the child's sense of stability." 11 Moreover, a de facto parent is entitled to legal recognition for serving in this capacity because it is fundamentally fair. ${ }^{12}$ For these reasons, the drafters seek to imbue de facto parents with new "rights." 13

${ }^{6}$ Mary Ann Glendon, Family Law and Family Policies in a Time of Turbulence, prepared for April 2004 Family Policies Congress of the Social Trends Institute. at 3 (on file with author). Loosening restrictions on access to divorce is one example of the creation of unintended consequences. At the same time that divorce has become easier to obtain, a growing body of literature documents its negative impact upon children, including dramatic economic decline, myriad behavioral problems, poorer performance in school, diminished earning capacity, and an increased probability of divorce as an adult. See, e.g., Judith S. Wallerstein et al., The Unexpected Legacy of Divorce: A 25 Year Landmark Study (2000).

${ }^{7}$ The parties principally impacted by this reform are nonmarital children and children after divorce, the vast majority of whom live with their mothers. Of the children who live with either their mother or father only, 83 percent live with a mother. U.S. Census Bureau, America's Families and Living Arrangements: 2003, tbl.C2 (2004), http://www.census.gov/population/socdemo/hh-fam/cps2003/tabC2-all.pdf(reporting that approximately 16.8 million children living with mother only versus approximately 3.3 million living with father only). Among divorced and separated couples with children, mothers maintain over four times as many households as fathers. U.S. Census Bureau, America's Families and Living Arrangements: 2003, tbl.FG6 (2004), http://www.census.gov/population/socdemo/hh-fam/cps2003/tabFG6-all-1.pdf (showing that approximately 1.3 million maintained by father versus approximately 5.3 million maintained by mother). In single parent homes where the couple never married, the disparity is slightly greater. $I d$. (finding that 852,000 maintained by father versus approximately 4.4 million maintained by mother). Given these facts, the creation and enlargement of parental "rights" for de facto parents, over the objection of the legal parent, will disproportionately infringe on the parental prerogatives of women.

It will also tie the hands of minority women more often than white women. See Sarah H. Ramsey, Constructing Parenthood for Stepparents: Parents by Estoppel and De Facto Parents Under the American Law Institute's Principles of the Law of Family Dissolution, 8 Duke J. Gender L. \& Pol'y 285, 287 (2001) (discussing how family formation patterns often differ by race).

${ }^{8}$ Principles ch. 1, Topic 1.I (d), at 5. The drafters are not alone in advancing the idea that what one does should count more than who one is. A number of commentators have argued that function should determine and define legal fatherhood more than mere biology. See, e.g., Leslie Joan Harris, Reconsidering the Criteria for Legal Fatherhood, 1996 Utah L. Rev. 461, 480 (arguing that "functional paternity" should be the basis for legal rights and duties because functioning as a parent is congruent with current social mores, and encourages and supports individuals who take on responsibility for children); David L. Chambers, Stepparents, Biologic Parents, and the Law's Perceptions of "Family" After Divorce, in Divorce Reform at the Crossroads 102, 117 (Stephen D. Sugarman \& Herma Hill Kay eds., 1990) ("[M]any individual stepparents do form strong emotional bonds with their stepchildren. They are seen by the child as 'parent.'”); Gilbert A. Holmes, The Tie That Binds: The Constitutional Right of Children to Maintain Relationships with Parent-Like Individuals, 53 MD. L. Rev. 358, 410 (1994) (arguing that the law should "grant[ ] parent-like individuals greater consideration than the current jurisprudence affords").

${ }^{9}$ Principles ch. 1, Topic 1.I (d), at 5.

${ }^{10}$ Principles $\$ 2.03 \mathrm{cmt}$. c.

${ }^{11}$ Principles ch. 1, Topic 1.I (d), at 5-6.

${ }^{12}$ Principles ch. 1, Topic 1.I (d), at 5-6 ("Traditionally, parenthood is an exclusive, all-or-nothing status. A child can have only one mother and only one father; others have no rights, regardless of their functional roles.").

${ }^{13}$ The Principles would also extend parent-like rights to another category of adults who live with a child, parents by estoppel. The defining characteristic of this group is that they accept responsibility for the child. See PrINCIPLES 
My aim in this chapter is not to take issue with the presence of these posited goods. ${ }^{14}$ No one doubts that some children will be made better off by preserving a connection with a de facto parent. ${ }^{15}$ But this gain may not be as great as we might think it would be by extrapolating from biological parents. New, carefully constructed studies of parental investment suggest that the level of investments that fathers make in children varies with the fathers' biological relatedness to the child. ${ }^{16}$ Moreover, whatever the magnitude of the gain for some children, it comes at a cost. A significant body of research suggests that giving men previously in relationships with a child's mother significant amounts of unsupervised parental access - as the ALI proposes to do - will result in more children being sexually exploited and physically abused. ${ }^{17}$

This chapter argues that before we grant Ex Live-In Partners new parental "rights," we must do more than simply posit good outcomes. Rather, policymakers, courts, and legislators should sum these probable effects, good and bad, to evaluate whether the approach is, on balance, a net good. Before any decisionmaker implements the ALI's proposed treatment of Ex Live-In Partners, they should be convinced that the ALI has met its burden of demonstrating that this creation and enlargement of parental rights would benefit children more than it would harm them. As Professor Eekelaar concludes so aptly with respect to the past caretaking standard, "But if it is to be presumed that an arrangement will be in a child's best interests, it must be clear that this will be so in an overwhelming majority of cases. In the absence of clear evidence that time matching will satisfy this, or even that this is what parents usually do by agreement, it fails as a presumption."18

In working out this calculus, this chapter discusses only one risk to children from conferring significantly expanded parent-like "rights" on Ex Live-In Partners: the possibility of sexual exploitation. This chapter focuses only on sexual abuse because it is sufficient to illustrate one probable harm some children will likely experience if we follow the ALI's recommendations. But sexual exploitation is by no means the only harm to which we would expose children by instituting a free-form, fluid conception of parenthood that encompasses every cohabitant with whom a woman shared equal caretaking responsibility for two years or more. Some of these children are likely also to experience punishing physical abuse and neglect. ${ }^{19}$

$\$ 2.03 \mathrm{cmt}$. b(ii), at 111-12. The legal recognition of parents by estoppel is justified in part by expectations of the parties. Principles $\$ 2.03 \mathrm{cmt}$. b(ii), at 112 ("When this reasonable good faith [that the individual is the parent] exists, the individual is seeking status based not solely on his functioning as a parent but on the combination of the parental functions performed and the expectations of the parties."). Legal recognition is also predicated on actions that are sufficiently clear and unambiguous to indicate parental status was contemplated by all. PRINCIPLES $\$ 2.03$ cmt. b(iii), at 114. Parents by estoppel will often have lived with the child since birth and believed themselves to be the child's biological parent. Principles $\$ 2.03$ (1)(b)(ii),(iii); Seger v. Seger, 542 A.2d 424 (Pa. Super. Ct. 1988) (granting partial custody and visitation to stepfather who lived with child's mother for two years when she informed him she was pregnant with his child and who raised and supported the child after she revealed he was not the father, until the couple's break up). This is important from a risk assessment perspective and possibly also to the benefits we would predict to children of continuing contact. See Parts II \& III infra. Consequently, the recommendations and critiques in this chapter are limited to the ALI's proposed treatment of de facto parents.

${ }^{14}$ The drafters assume that Ex Live-In Partners who performed caretaking tasks for a child have done so for benign reasons, not malign ones. As note 45 infra observes, the drafters confine their consideration of child abuse to abuse that "has occurred," neglecting the potential for future abuse.

${ }^{15}$ There is certainly no dearth of social science evidence suggesting some children will indeed benefit from continuing contact. See infra note 80.

${ }^{16}$ See infra Part II.

17 See infra Part III.

${ }^{18}$ Eekelaar, this volume.

${ }^{19}$ Children living with unrelated males are more vulnerable to physical abuse and other forms of child abuse. For instance, British children living with their mother and a cohabitant are 33 times more likely to be physically abused 
Because this argument hinges on the calculation of probable harms or goods resulting to children who have lived with a stepfather or the mother's unmarried live-in partner, it is necessarily limited. The research presented here sheds light only on the wisdom of giving to Ex Live-In Partners parent-like "rights" of access to children, without the moderating influence of a mother's presence. It cannot tell us anything at all about whether women in now-defunct relationships with a child's father should receive custody and visitation "rights," nor can it help us to evaluate whether to extend such rights to lesbian coparents. Both questions would involve a different set of calculations than presented here. ${ }^{20}$

This chapter evaluates whether the drafters' ballooning definition of parent has the potential for ill, as well as for good. Part I describes and critiques the ALI's proposed treatment of de facto parents. Part II reviews new studies that suggest that the upside to children of continuing contact with an Ex Live-In Partner may be more muted than the ALI assumes. Part III then provides a primer on factors affecting a child's risk of sexual abuse, and concludes that in this brave new world of newly anointed "parents," protective factors that might serve to shield a child from sexual victimization are not marshaled on behalf of the child. Part IV then examines the way in which sexual predators "groom" their victims and documents the significant overlap between "grooming" and the caretaking functions used to decide who qualifies as a de facto parent. Part V asks whether the test for de facto parents can be refined to select for "good risks," while culling out the bad and argues that an individualized decision based on the nature of the child's attachment to the Ex Live-In Partner would better promote the welfare of the children involved. Part VI concludes that the ALI - and more importantly, legislatures and courts that consider these proposals should not base such sweeping changes in parental rights on unsupported assumptions

and 73 times more likely to be killed than children living in an intact family. See Robert Whelan, Broken Homes and Battered Children: A Study of the Relationship Between Child Abuse and Family Type, tbls. 12 \& 14 (1994) (reporting a risk of physical abuse for children living with two natural married parents of 0.23 , compared to a risk of 7.65 for children living with their natural mother and a cohabitee and a risk of fatal abuse for children living with both natural, married parents of 0.31 , compared to a risk of fatal abuse of 22.9 for children living with their natural mother and a cohabitee). A child in a stepparent household is 120 times more likely to be bludgeoned to death than a child living with his genetic father in an intact household. Owen D. Jones, Evolutionary Analysis in Law: An Introduction and Application to Child Abuse, 75 N.C. L. Rev. 1117, 1208 (1997). New research focusing on all forms of child maltreatment has found that "[c] hildren who had a father surrogate living in the home were twice as likely to be reported for maltreatment after his entry into the home than those with either a biological father (odds ratio $=2.6,95 \%$ confidence interval $=1.4-4.7$ ) or no father figure in the home (odds ratio $=$ 2.0, 95\% confidence interval = 1.1-3.5)". Aruna Radhakrishna et al., Are Father Surrogates a Risk Factor for Child Maltreatment?, 6 (4) Child Maltreatment 281 (November 2001).

Similarly, Ania Wilczynski reports in an English sample of child-killing that the "proportion of male parentsubstitutes and male cohabitees [among child killers] were nine and fifty times" their respective rates in a national survey. Ania Wilczynski, Child Homicide 72-73 (1997). In an Australian sample, she found that nonbiological parents comprised 27 percent of the child-killers, although "only an estimated 7 percent of Australian children ... lived in step or blended families." $I d$.

${ }^{20}$ This is so because we know very little about child sexual abuse by women, other than it seems to occur very rarely. See Robin Fretwell Wilson, The Cradle of Abuse: Evaluating the Danger Posed by a Sexually Predatory Parent to the Victim's Siblings, 51 ЕмоRу L. J. 241, 245 n.13 (2002). Moreover, the principal risk to children of punishing physical abuse comes from father substitutes rather than from women. See Part III infra. It is worth noting, however, that an important impetus for permitting parental claims by de facto parents and parents by estoppel was to recognize same sex partners who cannot adopt one another's child or marry their partners. This desire to recognize same sex partners may have led to a number of unintended consequences and tensions explored here. To protect a mother's right to decide who has contact with her child without undermining the recognition many would like to extend to same-sex, non-biological parents may be tricky. Part V suggests that state legislators may want to address only the most compelling cases for significantly expanding rights for nonbiological caretakers - like the interests of same sex partners or of stepfathers who want to care for a child after the mother's death - and leave the less compelling cases untouched. 
about the value of continuing contact with Ex Live-in Partners, but must instead take account of and respond to the empirical research that bears on the wisdom of such fundamental change.

\section{The ALI Views Continuing Contact between Children and Ex Live-In Partners as an Unadulterated Good}

This part demonstrates that the drafters view continuing contact between children and men who shared caretaking with a child's mother for two years or more - whether married or unmarried - as an unadulterated good. It first outlines the substantive and standing rights the ALI seeks to confer upon an Ex Live-In Partner, and then critiques this treatment of de facto parents.

\section{A. ALI's Treatment of De Facto Parents}

As noted earlier, the drafters want to ensure continuing contact between a child and former partner of the child's parent, without - they argue - "unnecessary and inappropriate intrusion into the relationships between legal parents and their children." ${ }^{21}$ To accomplish this, their test for status as a de facto parent is, they urge, "strict:"22

(1) The individual must have lived with the child for a significant period of time (not less than two years), and acted in the role of a parent for reasons primarily other than financial compensation [described hereinafter as the "Residency Requirement"].

(2) The legal parent or parents must have agreed to the arrangement, or it must have arisen because of a complete failure or inability of any legal parent to perform caretaking functions [described hereinafter as the "Agreement Requirement"].

(3) In addition, the individual must have functioned as a parent either by (a) having performed the majority share of caretaking functions for the child, or (b) having performed a share of caretaking functions that is equal to or greater than the share assumed by the legal parent with whom the child primarily lives [described hereinafter as the "Caretaking Requirement"]. ${ }^{23}$

Significantly, there is no requirement that treatment as a de facto parent be in the best interests of the child, as is required for certain parents by estoppel. ${ }^{24}$

The Residency Requirement functions to exclude "neighbors, nonresidential relatives, or hired babysitters," 25 while the exclusion of relationships motivated by money is designed to cull out caretakers who are not "motivated by love and loyalty." ${ }^{26}$ Although the drafters seek to recognize "long-term, substitute parent-child relationship[s]," coresidence for as little as two years may qualify an adult as a de facto parent. ${ }^{27}$ The length of time that is considered "significant" will vary with the child's age, frequency of contact with the adult, and the intensity of their relationship. ${ }^{28}$ For children under six, two years "is likely to qualify as significant" while longer periods "may be required" for school-aged children, and "even longer" if the child is an adolescent. ${ }^{29}$

\footnotetext{
${ }^{21}$ Principles $\$ 2.03 \mathrm{cmt}$. c, at 119.

23 Principles $\$ 2.03 \mathrm{cmt}$. c, at 119 .

22 Principles $\$ 2.03 \mathrm{cmt}$. c, at 119 .

25 Principles $\$ 2.03 \mathrm{cmt}$. c (i), at 119-20.

${ }^{27}$ Principles $\$ 2.03 \mathrm{cmt}$. c (iii), at 122 .

24 See Principles $\$ 2.03(1)(\mathrm{b})$ (iii).

26 Principles $\$ 2.03 \mathrm{cmt}$. c (ii), at 120 .

28 Principles $\$ 2.03 \mathrm{cmt}$. c (iv), at 122 .

${ }^{29}$ Principles $\$ 2.03 \mathrm{cmt}$. c (iv), at 122 . The drafters seem unwilling to require additional years or to give clear signals that such additional amounts of time should be required. Instead they note that "[i]n some cases, a period longer
} 
A de facto parent relationship, the drafters tell us, "cannot arise by accident, in secrecy, or as a result of improper behavior" ${ }^{30}$ because it usually requires agreement. The Agreement Requirement limits de facto parent status generally "to those individuals whose relationship to the child has arisen with knowledge and agreement of the legal parent." ${ }^{\text {"1 }}$ Lack of agreement may be evidenced by the failure of the partner to adopt the child, if adoption was an option, ${ }^{32}$ as well as by the retention by the legal parent "of authority over matters of the child's care, such as discipline." 33

Although the Agreement Requirement requires "an affirmative act or acts by the legal parent demonstrating a willingness and an expectation of shared parental responsibilities," agreement may be implied by the circumstances. ${ }^{34}$ When two adults share roughly equal responsibility for a child, this equal caretaking by itself satisfies the agreement requirement. Consider illustration 22:

For the past four years, seven-year-old Lindsay has lived with her mother, Annis, and her stepfather, Ralph. During that period, Ralph and Annis both worked outside the home, and divided responsibility for Lindsay's care roughly equally between them.

Annis's sharing of responsibility for Lindsay's care with Ralph constitutes an implied agreement by her to the role assumed by Ralph. ${ }^{35}$

In short, any parent who acquiesces in her partner's decision to take on equal caretaking duties, would likely "have agreed" to the partner's claim of de facto parent status.

With respect to the Ex Live-In Partner's share of caretaking functions, he must have performed at least as much care as the legal parent herself provided. ${ }^{36}$ Caretaking functions consist of the chores necessary for the "direct delivery of day-to-day care and supervision to the child." ${ }^{37}$ They include "physical supervision, feeding, grooming, discipline, transportation, direction of the child's intellectual and emotional development, and arrangement of the child's peer activities, medical care, and education." 38 In the drafters' view, caretaking functions "are likely to have a special bearing on the strength and quality of the adult's relationship with the child" because they involve "tasks relating directly to a child's care and upbringing." 39

The Caretaking Requirement is central not only to the de facto parent's qualification qua de facto parent, but also to the allocation of time with the child, which the drafters label "custodial responsibility." 40 Section 2.08 of the PrinCIPLES generally seeks after the break-up to "approximate" those caretaking arrangements that preceded it. ${ }^{41}$ Thus, the

than two years may be required in order to establish that an individual has the kind of relationship that warrants recognition." Principles $\$ 2.03 \mathrm{cmt}$. c (iv), at 122 (emphasis added).

${ }^{30}$ Principles $\$ 2.03 \mathrm{cmt}$. c (iii), at $121 . \quad{ }^{31}$ Principles $\$ 2.03 \mathrm{cmt}$. c (iii), at 121 .

32 Principles $\$ 2.03 \mathrm{cmt}$. c, at 119 (noting that absence of adoption when available would not be dispositive, but would be "some evidence" of lack of intent to agree).

${ }^{33}$ Principles $\$ 2.03 \mathrm{cmt}$. c (iii), at 121 . No agreement is required where there has been a "total failure or inability by the legal parent to care for the child." Id.

${ }^{34}$ Principles $\$ 2.03 \mathrm{cmt}$. c (iii), at 121 . $\quad{ }^{35}$ Principles $\$ 2.03$, illus. 22, at 122.

${ }^{36}$ Principles $\$ 2.03 \mathrm{cmt}$. c (v), at 123 . The one exception to this is where the legal parent is a noncustodial parent, in which case the parent's partner will not satisfy the criterion. $I d$.

${ }^{37}$ Principles $\$ 2.03 \mathrm{cmt}$. g, at 125 . ${ }^{38}$ Principles $\$ 2.03 \mathrm{cmt}$. g, at 125 .

${ }^{39}$ Principles $\$ 2.03 \mathrm{cmt}$. g, at 125 . The drafters themselves recognize this as "an assumption." Id.

${ }^{40}$ See Principles $\$ 2.08(1)$, at 178.

${ }^{41}$ See Principles $\$ 2.08(1) \mathrm{cmt}$. a, at 180 . The drafters want to resist "express[ing] particular preferences about what is best for children," because rules favoring sole custody over joint, or vice versa, "do not reflect the preferences, experiences, or welfare of all families." Id. $\$ 2.05 \mathrm{cmt}$. a, at 146 (explaining their selection of the approximation standard). No rule is neutral, however, even this default to past caretaking practices. The drafters have chosen not only to replicate past actions, but to give Ex Live-In Partners greater entitlement to partial custody. 
"approximation" or "past caretaking" standard requires that "the proportion of time the child spends with each parent [approximate] the proportion of time each parent spent performing caretaking functions for the child prior to the parents' separation," unless an exception applies. ${ }^{42}$ The justification for this arrangement is that "the division of past caretaking functions correlates well with other factors associated with the child's best interests, such as the quality of each parent's emotional attachment to the child and the parents' respective parenting abilities." 43 The rights of access that the PRINCIPLES would give to Ex Live-In Partners appear to include unsupervised visitation and overnight stays. Supervised visits are reserved for those instances when protecting the child or the child's parent is warranted, as when the courts finds "credible evidence of domestic violence." ${ }^{4}$

As Professor Levy notes in this volume, exceptions for departing from the past caretaking standard are available to protect the child or a parent from the other parent's neglect or abuse, domestic violence, or drug or alcohol abuse; ${ }^{45}$ to accommodate an older child's preferences; to protect a child from the harm that would result from the rule's application "because of a gross disparity in the quality of the emotional attachment between each parent and the child or in each parent's demonstrated ability or availability to meet the child's need;" and to avoid allocations that "would be extremely impractical or that would interfere substantially with the child's need for stability...;" among other things. ${ }^{46}$ Generally, however, if an Ex Live-In Partner puts in half the work involved in caring for a child, he gets as much as half the time, ${ }^{47}$ subject to the practical constraints of splitting time with a child fifty-fifty, as explained more fully below.

${ }^{42}$ Principles $\$ 2.08$. Section 2.03(5) defines "caretaking functions" as "tasks that involve interaction with the child or that direct, arrange, and supervise the interaction and care provided by others." A nonexclusive list of caretaking functions includes such matters as "satisfying the nutritional needs of the child," "directing the child's various developmental needs," "providing discipline," "supervising chores," "performing other tasks that attend to the child's needs for behavioral control and self-restraint," "arranging for the child's education," "providing moral and ethical guidance," and a host of other specified functions. Id. $\$ 2.03(5)(\mathrm{a})-(\mathrm{h})$. Section 2.03(3) makes clear that "custodial responsibility" "refers to physical custodianship and supervision of a child. It usually includes, but does not necessarily require, residential or overnight responsibility." Section 2.03(6) defines "parenting functions," a phrase which appears only in Section 2.09(2) (see infra note 50), to include "tasks that serve the needs of the child or the child's residential family," such as "caretaking functions" and a diverse variety of other functions, from "providing economic support," "yard work, and house cleaning," to "participating in decision-making regarding the child's welfare" and "arranging for financial planning." Principles $\$ 2.03(6)$.

${ }^{43}$ See Principles $\$ 2.08(1) \mathrm{cmt}$. b, at 182.

${ }^{45}$ The drafters do care about child abuse, but the inquiry is essentially backward-looking, asking judges and others to identify only those cases "in which there is credible evidence that child abuse ... has occurred." Principles ch. 1, Topic 1.II(e), at 6-7. See also Principles $\$ 2.05$ (3), at 144 (outlining elements of parenting plan). Section 2.05(3) directs courts to screen cases for child abuse or domestic violence. A court-monitored screening process is necessary "[s]ince parents often are not forthcoming about the existence of child abuse and domestic abuse." Principles $\$$ $2.05 \mathrm{cmt}$. c, at 147. During this screening process, the focus is on what already "has occurred." This phrase appears five times in Section 2.05(3) and comment c explaining it, while no mention is explicitly made about the potential for future abuse per se. If domestic violence is brought to a court's attention, the court must decide on whether abuse has occurred when considering a parenting plan. See id. \$2.11(1)(a), at 255.

${ }^{46}$ Levy, this volume.

${ }^{47}$ Parkinson, this volume (reviewing the drafters' illustrations of the past caretaking standard and exceptions to it, and concluding that while "it is accepted that if the parents have shared equally in the caretaking of the children, then an allocation of equal custodial time would ordinarily be warranted," most of the Illustrations focus on exceptions to the standard, rather than the standard's usual application, and therefore create some confusion about the strength of the past caretaking standard as a determinant of care arrangements after the adults break up). Professor Parkinson notes that at least one drafter shared the view that equal caretaking will generally result in roughly equal time. Id. (citing Katharine T. Bartlett, U.S. Custody Law and Trends in the Context of the ALI Principles of the Law of Family Dissolution, 10 VA. J. Soc. PoL'y \& L. 5, 18 (2002) ("If parents equally shared caretaking responsibilities, that fact will be reflected in the custodial allocations.")). 
Section 2.04 does two things: it allows an Ex Live-In Partner who lived with the child during the previous six months to bring an action, ${ }^{48}$ and then it gives him substantive rights. ${ }^{49}$ In terms of substantive rights, the Ex Live-In Partner will have a claim to an equal share of the custodial responsibility for a child, subject to three limits. First, a de facto parent may not receive a majority of the custodial responsibility for a child over the objection of the child's legal parent or parent by estoppel, unless that parent has not been performing a reasonable share of the child's parenting. ${ }^{50}$ Second, although a de facto parent can receive some decision-making responsibility for a child, he is not presumptively entitled to this, as a legal parent or parent by estoppel would be. ${ }^{51}$ Third, a de facto parent does not get presumptive access to a child's school or health records, as other parents do under the Principles. ${ }^{52}$ In addition to these specific limitations, there is the general exception to the past caretaking standard, noted above, that provides that a de facto parent should not receive an allocation of time with the child if making such an award would be impractical. ${ }^{53}$

To make this more concrete, consider illustration 1 to Section 2.18. There, Barbara marries Randall and for four years acts as the primary caretaker for his two children from a prior marriage. ${ }^{54}$ Randall supports the family economically and provides backup care. At divorce, "assuming Barbara satisfies the definition of a de facto parent," she "may be allocated a coequal share of responsibility with Randall," or a "smaller share" if practicality so dictates. ${ }^{55}$ However, because Randall has been performing a reasonable share of parenting functions, Barbara will not receive "the majority share of custodial responsibility for the children unless Randall agrees, or unless she shows that an

\footnotetext{
${ }^{48}$ Section 2.04 gives standing and notice rights to a de facto parent who "resided with the child within the six-month period prior to the filing of the action or who has consistently maintained or attempted to maintain the parental relationship since residing with the child." Principles $\$ 2.04(1)(\mathrm{c})$, at 134 . The six-month window is waived if the de facto parent "consistently maintained or attempted to maintain the parental relationship since no longer sharing the same residence." $I d . \$ 2.04 \mathrm{cmt}$. d, at 136. This waiver "eliminate[s] the advantages of uncooperative or strategic behavior by the custodial parent." Id.

${ }^{49}$ Principles $\$ 2.04$, Reporter's Notes, cmt. a, at 139-40.

${ }^{50}$ Principles $\$ 2.18$. Parenting functions means “tasks that serve the needs of the child or the child’s residential family," including not only caretaking functions but also "providing economic support; participating in decisionmaking regarding the child's welfare; maintaining or improving the family residence, including yard work, and house cleaning; doing and arranging for financial planning and organization, car repair and maintenance, food and clothing purchases, laundry and dry cleaning, and other tasks supporting the consumption and savings needs of the household; performing any other functions that are customarily performed by a parent or guardian and that are important to a child's welfare and development; arranging for health-care providers, medical follow-up, and home health care; providing moral and ethical guidance; and arranging alternative care by a family member, babysitter, or other child-care provider or facility, including investigation of alternatives, communication with providers, and supervision of care." Principles $\$ 2.03(6)$.

${ }^{51}$ Principles $\$ 2.09 \mathrm{cmt}$. c, at $240 . \quad{ }^{52}$ Principles $\$ 2.09(4)$.

${ }^{53}$ Illustration 4 to Section 2.18 demonstrates the limitation that workability places upon the arrangements that a court may make. There, a child, Keith, has two parents who have received custodial rights after their divorce, Elena and Lee. Elena's second husband, Lincoln, also received every other weekend with Keith upon his divorce from Elena since he "assumed the majority of responsibility for Keith's upbringing while Elena returned to school to finish her medical training." Elena married Norman, who with Elena's consent provided as much care for Keith as Elena. The Principles note that although Norman would ordinarily warrant an allocation of custodial responsibility if he meets the test for de facto parent, "[t]he court may determine that allocating custodial responsibility to four different adults now living in four different households is impractical and contrary to Keith's interests. If so, the court should limit or deny an allocation of responsibility to Lincoln, or Norman, or both of them." PRINCIPLES $\$ 2.18$, illus. 4 .

${ }^{54}$ Principles $\$ 2.18$, illus. 1 .

${ }^{55}$ Princip Les $\$ 2.18$, illus. 1 (concluding that Barbara "should be allocated whatever share of custodial responsibility for the children is determined to be appropriate under $\$ 2.08$, but as limited by $\S 2.18(1)$," which prohibits the de facto parent from receiving a majority of the caretaking responsibility and limits allocations if they would be impractical).
} 
allocation of the majority of custodial responsibility to Randall would be harmful to them." 56

It is important to recognize the magnitude of the shift the ALI proposes. Without the ALI's proposed reforms, an Ex Live-In Partner would have standing only in a minority of jurisdictions. ${ }^{57}$ Although a growing number of jurisdictions already give standing to nonparents, many of these limit standing only to grandparents or stepparents. ${ }^{58}$ Very few permit unmarried cohabitants to initiate actions for custody or visitation..$^{59}$ Contrast the ALI's proposed reforms with the Uniform Marriage and Divorce Act, which allows an action by "a person other than a parent, ... but only if [the child] is not in the physical custody of one of his parents." ${ }^{\prime 60}$ There, an emergency - the absence of legal parents necessitates standing by others. Here, we have third parties, unrelated adults, given the opportunity to tread on the parental prerogatives of the legal parent. In the absence of the Principles, an Ex Live-In Partner today would likely receive some limited visitation in certain jurisdictions with the child after the breakup, but nothing that approaches the allocations of time that the ALI proposes to give. As Professor Jane Murphy noted in a recent review of de facto parent cases, a "few states and a handful of courts have granted nonbiological, non-marital caretakers such as stepfathers... rights similar to those granted legal fathers," but "these cases generally limit the parental rights to visitation." 61

Like all custody rules, ${ }^{62}$ the rights the ALI seeks to create in some jurisdictions and enlarge in others only come into play when the legal parent does not willingly grant visitation to her ex-partner. ${ }^{63}$ A mother can always decide voluntarily to provide visitation to those men she thinks will enrich her child's life.

Interestingly, the ALI would extract very little from Ex Live-In Partners in exchange for this significant enlargement of parental rights. As Professor Katharine Baker points out in this volume, the Principles impose child support obligations on parents by estoppel but not on de facto parents. ${ }^{64}$ This choice is perplexing since live-in partners benefit children by providing them with additional financial support during the intact adult relationship and presumably could do so to some degree afterwards. ${ }^{65}$

\footnotetext{
${ }^{56}$ Principles $\$ 2.18$, illus.1.

57 See Principles $\$ 2.04$, Reporter's Notes, cmt. d, at 140 (noting the "traditional rule... that a nonparent cannot file an action for custody or visitation without a showing that the parents are unfit or unavailable").

${ }^{58}$ Principles $\$ 2.04$, Reporter's Notes, cmt. a, at 140 .

${ }^{59}$ See, e.g., Cooper v. Merkel, 470 N.W.2d 253, 255-56 (S.D. 1991) (denying visitation to mother's ex-boyfriend who as a father figure had assumed responsibility for raising her son for seven years); Engel v. Kenner, 926 S.W.2d 472 (Mo. Ct. App. 1996) (denying joint custody to boyfriend of mother who lived with mother and child for five months and helped support child for three years thereafter).

${ }^{60}$ Unif. Marriage \& Divorce Act $\$ 401(\mathrm{~d})(2)$, 9A U.L.A. 264 (1998).

${ }^{61}$ Jane Murphy, Legal Images of Fatherhood: Welfare Reform, Child Support Enforcement, and Fatherless Children, 81 Notre Dame L. Rev. 325, 342-343 (2005).

${ }^{62}$ Of course, the problem extends beyond those instances in which the legal parent does not voluntarily grant visitation to her ex-partner. By conferring legal standing and "rights" on ex-partners to seek custody and visitation, the drafters make it all the more difficult for mothers to say no. See Robert H. Mnookin \& Lewis Kornhauser, Bargaining in the Shadow of the Law: The Case of Divorce, 88 YALE L.J. 950 (1979).

${ }^{63}$ The drafters seek to confer custody and visitation rights "over the opposition of the legal parent." Principles $\$ 2.03$, Reporter's Notes, cmt. b, at 129 (discussing equitable doctrines conferring such rights).

${ }^{64}$ Baker, this volume.

${ }^{65}$ See Sarah H. Ramsey, Stepparents and the Law: A Nebulous Status and a Need for Reform, in StepParenting: Issues in Theory, Research and Practice 217, 228 (Kay Pasley \& Marilyn Ihinger-Tallman eds., 1994).

The ALI's decision to give Ex Live-In Partners parental rights without requiring child support may also represent a missed child protection opportunity. The ALI could have limited standing as a de facto parent to those adults who voluntarily assume a child support obligation to a child, which would serve an important screening function. It
} 


\section{B. Critique of the ALI's Treatment of De Facto Parents}

If state legislatures or courts institute these proposals, many mothers will find themselves unable to excise former lovers from their lives and the lives of their children. This should trouble us. As Professor Karen Czapanskiy observes: "For [the caregiver] to do the job to the best of her or his abilities, [they] need[] authority as well as responsibility.... The autonomy of the lead caregiver must be respected." 66 The Agreement Requirement is a weak reed of protection against such a dramatic and unexpected result. A partner's interest in and interaction with her children presumably is a desired goal of most women, and is likely to be warmly received. What mother would not allow her husband or live-in partner to read to her child, help put the child to bed and wake him or her up in the morning, and otherwise share caretaking responsibility? The fact that many of these actions may be undertaken with the legal parent's consent in an ongoing relationship seems to say very little about the legal parent's expectations after the relationship's demise. $^{67}$

It was unnecessary to stretch the tent of parenthood this far. Many live-in partners who want to protect their interests in an existing adult-child bond after their relationship ends with the child's mother, can adopt the child. ${ }^{68}$ Moreover, the drafters' provision of standing to nonparents when it serves the best interests of the child would have accommodated the most compelling claims for standing to seek custody and visitation with a child, ${ }^{69}$ without encompassing every Tom, Dick, and Harry with whom a woman cohabits for two years and shares an equal caretaking load.

Despite acknowledging that legal parents exhibit the "maximum commitment to the parenting enterprise," 70 the drafters make no inquiry, when providing standing and an allocation of custodial responsibility, into the reasons for the legal parent's objection. ${ }^{71}$ Perhaps she ended the relationship because of his interaction with her child. ${ }^{72}$ Other than stock observations about emotions running high at the time of breakup, ${ }^{73}$ the drafters have no more reason to believe that when a mother withholds access she does so out of spite or selfishness than they do for believing that she is motivated

would promote continuing contact between children and those adults who have committed to a child in concrete, palpable ways - where continuing contact is likely to create the greatest gains for a child - while possibly helping to screen out "bad risks." See Parts II, III and IV infra.

${ }^{66}$ Karen Czapanskiy, Interdependencies, Families, and Children, 39 Santa Clara L. Rev. 957, 979-80, 1029 (1994).

${ }^{67}$ Contrast this with coparents who have set forth an understanding in writing about how a child will be parented, where it may well be the expectation of the parties to share parental responsibilities during the relationship and after. Principles $\$ 2.03 \mathrm{cmt}$. c (iii), at 121 .

${ }^{68}$ Principles $\$ 2.03 \mathrm{cmt}$. c, at 119 (noting that adults can protect their interest in a relationship with a child by adopting the child "if available under applicable state law").

${ }^{69}$ Principles $\$ 2.04$ (2) (giving the court discretion "in exceptional cases, ... to grant permission to intervene, under such terms as it establishes, to other individuals... whose participation in the proceedings under this Chapter it determines is likely to serve the child's best interests").

${ }^{70}$ Principles ch. 1, Topic 1.I (d), at 5-6.

${ }^{71}$ The one exception to this is for past or ongoing abuse, but not mere queasiness that something is not right about a partner's interaction with a child.

${ }^{72}$ Diana E. H. Russell, The Secret Trauma: Incest in the Lives of Girls and Women 372 (1986) (reporting that one in four nonoffending mothers suspected the abuse shortly before the child's disclosure).

${ }^{73}$ Principles $\$ 2.08 \mathrm{cmt}$. b, at 183 (observing, in a discussion of the rationale for the past caretaking standard, that the parties' "expectations and preferences are often complicated at divorce by feelings of loss, anxiety, guilt, and anger-feelings that tend not only to cloud a parent's judgment and ability to make decisions on behalf of the child, but also to exaggerate the amount of responsibility a parent wants to assume for a child, or the objections he or she has to the other parent's level of involvement in the child's life"). 


\begin{tabular}{|c|}
\hline Net Good if and only if: \\
Expected Goods (Probability x Magnitude) \\
Expected Harms (Probability x Magnitude) \\
\hline $\begin{array}{c}\text { Some Assumptions: } \\
\text { Predicted Goods (Probability } \Uparrow \times \text { Magnitude } ? / \Downarrow) \\
- \\
\text { Predicted Harms (Probability } \Downarrow_{x} \text { Magnitude } \Uparrow \text { ) }\end{array}$ \\
\hline
\end{tabular}

Figure 5.1. Assessing the ALI's Treatment of Ex Live-In Partners.

by concern for the best interests of her child. ${ }^{74}$ Moreover, one can easily imagine that the rights the ALI seeks to confer on Ex Live-In Partners could be exploited not as an opportunity to stay in the children's lives, but as an opportunity to control a child or her mother.

Further, conferring new parental rights is not without cost. By granting standing to Ex Live-In Partners, we would encourage the adults involved to resolve problems in court, with all the costs and damaged relationships that result. We would also encourage litigation by conferring substantive rights on Ex Live-In Partners. It may be important to encourage continuing relationships with Ex Live-In Partners, but long, expensive custody fights - even where the mother wins - have financial and emotional costs that hurt her and the child. This is particularly worrisome as a risk because the definition of de facto parent requires such complex fact finding. Nonetheless, the drafters latch onto bright-line, easily verifiable time requirements in an effort to avoid expensive and, in their view, generally counterproductive inquiries into the qualitative nature of the relationship being preserved. Such inquiries are counterproductive both because they "draw[] the court into comparisons between parenting styles and values that are matters of parental autonomy not appropriate for judicial resolution," 75 and because they require expert testimony which, in the "adversarial context, tends to focus on the weaknesses of each parent and thus undermines the spirit of cooperation and compromise necessary to successful post-divorce custodial arrangements." 76

A time test also obscures the underlying "good" for which the time requirement serves as a proxy - the depth and quality of the adult-child relationship. Attachment may well safeguard a child who has contact with that adult after the breakup. ${ }^{77}$ Yet it plays no part in the ALI's assessment of who counts as a de facto parent and has standing to seek such rights of access. Neither is attachment explicitly considered in awarding visitation and custody, unless there is a "gross disparity in the quality of the [child's] emotional attachment" with each parent. ${ }^{78}$

\footnotetext{
${ }^{74}$ As the Principles observe, "[t]he law grants parents responsibility for their children based, in part, on the assumption that they are motivated by love and loyalty, and thus are likely to act in the child's best interests." Principles $\$ 2.03 \mathrm{cmt}$. c (ii), at 120.

${ }^{75}$ PrinCIPLES $\$ 2.08 \mathrm{cmt}$. b, at 181-82 (making this observation about the "best interests" test and arguing that the approximation standard "yields more predictable and more easily adjudicated results, thereby advancing the best interests of children in most cases without infringing on parental autonomy").

${ }^{76}$ Principles $\$ 2.08 \mathrm{cmt}$. b, at 181-82.

${ }^{78}$ See Principles $\$ 2.08(1)(\mathrm{d})$.
} 


\section{The ALI Fails to Take into Account the Repercussions of Including Ex Live-In Partners in Children's Lives}

As noted above, the drafters construct a benign explanation for why an Ex Live-In Partner should have access to the child of their former partner. For the drafters, the impulse is at once selfless and selfish, grounded in a desire to continue an important parent-child relationship. Having largely assumed the possibility of an upside - one half of the calculus shown in Figure 5.1 - the drafters abruptly conclude that continuing contact between de facto parents and the children of their former lovers is an unqualified good for children.

Missing from this account is a critical, in-depth examination of the degree of gain children are likely to experience from continuing contact with an Ex Live-In Partner after the adults' relationship dissolves. Entirely absent from this account is the possible downside, the second half of the equation shown in Figure 5.1. ${ }^{79}$ While we may expect that some children (perhaps even the overwhelming majority) will be made better off, to some degree, ${ }^{80}$ we should also affirmatively expect that others will be made worse off, and profoundly so. ${ }^{81}$ This is so because many sex offenders use adult relationships to gain sexual access to children, ${ }^{82}$ and the PrINCIP LEs could be employed to give them continuing access to child victims.

The next two parts argue that imbuing adults with parental rights merely because they resided with a child and shared equal caretaking chores may not yield the welfare benefits for children that we might hope for, especially in light of the fact that the rights of continuing contact do not carry a concomitant duty to financially support these children. Equally important, any gains for children will come at a price. The ALI proposal would stretch the "parenthood" tent so wide that it will necessarily encompass some men with less-than-admirable motives or impulses.

\footnotetext{
${ }^{79}$ Although they have not examined the particular set of risks being examined here, scholars generally agree that the "definition of parent should be expanded or curtailed only when doing so serves to further the child's interests." Janet Leach Richards, Redefining Parenthood: Parental Rights Versus Child Rights, 40 Wayne L. Rev. 1227, 1229 (1994).

${ }^{80}$ For an excellent recitation of the social science evidence that many children will benefit from continuing contact, see Katharine T. Bartlett, Rethinking Parenthood as an Exclusive Status: The Need for Legal Alternatives When the Premise of the Nuclear Family Has Failed, 70 VA. L. Rev. 879, 902 (1984) (citing social science evidence that a "[n]ear consensus" exists that a child's healthy growth depends upon the continuing of his personal relationships). See also Holmes, supra note 8, at 389-90 (noting "the current consensus remains that children benefit from continued contact with non-custodial parents"); Kaas, supra note note 79, at 1119 (examining the "psychological harm to the child" that would result from a change in custody in favor of or contrary to a nongenetic caretaker).

Other scholars have analyzed the "findings of the recent research on the stepparent relationship," and concluded that "insofar as the needs of children are concerned, economic considerations suggest that remarriage is typically beneficial." Chambers, supra note 8 , at 102, 108. The "surge of research on the stepparent relationship," id. at $102-03$, is useful in determining whether a child benefits from stepparents who are in an intact relationship with the child's legal parent, but is less helpful in assessing the risks and benefits to a child of continuing contact after the adults break up.

${ }^{81}$ See infra note note 178 and accompanying text (noting that abuse inflicted by father substitutes is among the most depraved and injurious).

Of course, there are other costs to giving de facto parents parental rights. In her seminal article in the Virginia Law Review, Katharine Bartlett, one of the three drafters of the Principles, concluded that the "key disadvantages of broadening access to parenthood" are the increase in "the number of adults making claim to a child and enhanc[ing] the indeterminacy that already exists in child custody law." Bartlett, supra note 80, at 945.

${ }^{82}$ See infra Part III.B.
} 


\section{Evaluating the Upside to Children from Continuing Contact with Ex Live-In Partners}

"A limited but growing number of studies examine the social well-being of children living in cohabiting parent families." 83 Two recent, carefully constructed studies continue this work, using very different analytical tools. The first study, by Manning and Lamb, evaluates outcomes for children raised by biological and nonbiological fathers and compares these to outcomes for children raised only by their mothers. ${ }^{84}$ The second study, by Hofferth and Anderson, examines differential investments in children by biological and nonbiological fathers. ${ }^{85}$ As a pair, these studies provide a valuable lens for assessing the relative importance of biology as a factor affecting children's welfare and the incentive various fathers have to invest in children.

\section{A. The Importance of Biological Ties for Child Well-Being}

Manning and Lamb examined the well-being of adolescents in various families and asked (1) whether teenagers who live with their mother and her partner, whether married ("stepfathers") or unmarried ("mother's cohabitant"), do as well academically and behaviorally as teenagers living with two married, biological parents, and (2) whether these children fare better or worse than children living with single mothers. ${ }^{86}$ The results of this analysis indicate that children living with a stepfather or mother's cohabitant are more likely than children living with two married, biological parents to be expelled from school, exhibit greater levels of delinquency, and encounter more school problems ${ }^{87}$ Additionally, these children are more likely to have a lower grade point average and generally greater odds of achieving lower grades; they also score lower on the Peabody Picture Vocabulary Test ("PPVT") ${ }^{88}$ As the authors note, none of this is surprising. Children living in two married, biological parent families "generally fare better than teenagers living in any other family type." 89

What was novel and perhaps even surprising were Manning and Lamb's findings when they shifted the frame of reference from two married, biological parent families to single

${ }^{83}$ Wendy D. Manning \& Kathleen A. Lamb, Adolescent Well-Being in Cohabiting, Married, and Single-Parent Families, 65 J. Marriage \& FAM. 876, 878 (2003).

${ }^{84}$ Manning \& Lamb, supra note 83 , at 876.

${ }^{85}$ Sandra L. Hofferth \& Kermyt G. Anderson, Are All Dads Equal?: Biology Versus Marriage as a Basis for Paternal Investment, 65 J. Marriage \& FAM. 213 (2003).

${ }^{86}$ Manning \& Lamb, supra note 83, at 876. The authors evaluated data from the first wave of the National Longitudinal Adolescent Study of Adolescent Health (Add Health), which was based on interviews done in 1995 with students in grades 7 through 12 and their parents from a sample of 80 high schools and 52 middle schools in the United States. Id. at $880-81$.

${ }^{87} \mathrm{Id}$. at $885-86$ tbl. 3 (using married two parent families as a reference category, and finding that teens who lived with mother's cohabitant were more likely to be expelled from school $(.80, \mathrm{p}<.001)$, exhibit greater levels of delinquency $(1.32, \mathrm{p}<.01)$, and encounter more school problems $(.76, \mathrm{p}<.001)$; while children living with a stepfather were more likely to be expelled from school $(.56, \mathrm{p}<.001)$, exhibit greater levels of delinquency $(.61, \mathrm{p}<.01)$, and encounter more school problems $(.69, \mathrm{p}<.001))$.

${ }^{88} \mathrm{Id}$. (using married two parent families as a reference category, and finding that teens who lived with mother's cohabitant were more likely to receive low grades $(.64, \mathrm{p}<.001)$ and have lower vocabulary scores $(-2.36$, $\mathrm{p}<.01)$; while children living with a stepfather were more likely to receive low grades $(.52, \mathrm{p}<.001)$, and have lower vocabulary scores although the difference was not statistically significant).

${ }^{89}$ Id. at 885; Robin Fretwell Wilson, Evaluating Marriage: Does Marriage Matter to the Nurturing of Children?, 42 SAN Diego L. Rev. 847 (2005). 
mother families. There they found that children living with stepfathers or mother's cohabitants "have similar odds of being suspended or expelled as their counterparts living in single-mother families." than teens living with single mothers," while teens living with mother's cohabitant experienced more delinquency, although the difference receded when other variables were taken into account. ${ }^{91}$ Teens in all three households experience similar levels of trouble in school and possessed similar verbal skills and college expectations. ${ }^{92}$

Although they found "differences at the bivariate level... in terms of delinquency and low grades in school" between teens living with single mothers and those living with stepfathers, Manning and Lamb concluded that "teenagers living with unmarried mothers do not seem to benefit from the presence of their mother's cohabiting partner." ${ }^{13}$ Consequently:

$[\mathrm{M}]$ en's presence alone seems neither sufficient nor necessary to create positive outcomes for children. Indeed, our results show that stepfathers (married or cohabiting) provide limited benefit when contrasted with single-mother families. Our findings suggest that neither parental cohabitation nor marriage to a partner or spouse who is not related to the child (stepfamily formation) is associated with uniform advantage in terms of behavioral or academic indicators to teenagers living in single-mother families. ${ }^{94}$

Manning and Lamb note that their "results are consistent with research focusing on behavior problems." ${ }^{\prime 95}$

\section{B. The Importance of Biological Ties for Paternal Investments}

Studies of outcomes for children by family type suffer from an obvious limitation: a poorer outcome may be due to family form, but it may also be the result of other factors. For instance, differences in outcomes for children in two biological parent, married families versus those in cohabiting families may be attributable to a host of differences between these families, including income, relative youth of the parents, higher levels of stress and conflict, ${ }^{96}$ role confusion, or a lack of clear expectations about parenting in cohabiting households. ${ }^{97}$ Unlike outcome studies, a focus on investment avoids the multitude of reasons why groups of children may fare better or worse than others on average. ${ }^{98}$

${ }^{90} I d$. at $886-87$ \& tbl.4 (using single mother households as a reference category, and finding that teens who lived with mother's cohabitant had similar odds of being expelled or suspended, whether in the bivariate model or the multivariate model) were more likely to be expelled from school $(.80, \mathrm{p}<.001)$, exhibit greater levels of delinquency $(1.32, \mathrm{p}<.01)$, and encounter more school problems $(.76, \mathrm{p}<.001)$; while children living with a stepfather were more likely to be expelled from school $(.56, \mathrm{p}<.001)$, exhibit greater levels of delinquency $(.61, \mathrm{p}<.01)$, and encounter more school problems $(.69, \mathrm{p}<.001))$.

${ }^{91} I d$. at 886-87 \& tbl.4 (finding that teens who lived in single mother households experienced less delinquency $(-.76$, $\mathrm{p}<.05)$ than those who lived with mother's cohabitant, although the difference receded to a statistically insignificant -0.06 after a multivariate analysis).

${ }^{92}$ Manning \& Lamb, supra note 83, id. at 886-87 \& tbl.4 (noting that adolescents who live with stepfathers score higher on the vocabulary test than teens who live with mother's cohabitants but that this effect is marginally significant ( $\mathrm{p}=.06)$ after a multivariate analysis).

${ }^{93}$ Id. at 890 .

${ }^{94}$ Id. at 890 .

${ }^{95} \mathrm{Id}$. at 890.

${ }^{96}$ Anne Case et al., How Hungry is the Selfish Gene?, 110 Econ. J. 781, 782 (2000) (making this observation about stepchildren versus children in nuclear families).

${ }^{97} \mathrm{Id}$. (making this observation about stepparent households).

${ }^{98}$ Robin Fretwell Wilson, A Review of From Partners to Parents: The Second Revolution in Family Law by June Carbone, 35 FAM. L.Q. 833 (2002). 
Hofferth and Anderson examined levels of residential father involvement, comparing children living with biological fathers to children living with nonbiological fathers (stepfathers and mother's cohabitants). ${ }^{99}$ They compared investments in children by married, biological fathers, stepfathers (married but nonbiological parents), and mother's cohabitant family (unmarried, nonbiological parents), all of whom resided with the child. ${ }^{100}$ Hofferth and Anderson measured "parental involvement" in terms of time children spent actively engaged with their father; ${ }^{101}$ weekly hours when the father was available to the child but not actively engaged with the child; ${ }^{102}$ number of activities the father participated in with the child in the past month; ${ }^{103}$ and "warmth" toward the child, as reported by fathers themselves. ${ }^{104}$

Hofferth and Anderson conclude that the investments fathers make in their children are significantly influenced by biological-relatedness. ${ }^{105}$ They confirmed, as initially hypothesized, that children spent significantly more time actively engaged with a married, biological father than with a nonbiological father, whether a stepfather or mother's cohabitant. Specifically, married biological fathers spent 15.63 hours per week engaged with their child, compared to 9.15 hours for stepfathers and 10.10 for mother's cohabitants. ${ }^{106}$ Hours available fell off for stepfathers when compared to married biological fathers, but increased for mother's cohabitants: 13.35 hours per week for married biological fathers, 10.94 hours for stepfathers and 17.24 for mother's cohabitants. ${ }^{107}$ With regard to activities, children did significantly fewer activities with nonbiological fathers, whether stepfathers or mother's cohabitants. Married biological fathers engaged in 9.13 activities with their biological child over the course of a month, while stepfathers engaged in 8.22 activities and mother's cohabitants engaged in 7.43 activities. ${ }^{108}$ Finally, with regard to warmth, biology correlated positively with fathers' own assessment of the warmth they felt toward the children with

${ }^{99}$ Hofferth \& Anderson, supra note 85, at 223.

${ }^{100} \mathrm{Id}$. at 218-19. Hofferth and Anderson used data from the 1997 Child Development Supplement to the Panel Study of Income Dynamics, a 30-year longitudinal survey of a representative sample of United States men, women, children, and the families with whom they resided. The study sample represented 2,522 children who were reported by the primary caregiver to be living with an adult male, "either their biological father, a stepfather who is a nonbiological father married to the mother, or their mother's cohabiting partner." id. at 219.

${ }^{101} \mathrm{Id}$. This figure was obtained using a time diary of the child's activities, as reported by the child and/or the child's mother, including the question "[w] ho was doing the activity with [the] child?" The diary captured one weekday and one weekend day. Figures for the weekday (multiplied by five) were added to the figure for the weekend day (multiplied by two) to arrive at a weekly figure. Id. at 220.

102 Hofferth \& Anderson, supra note 85, at 219. This was also accomplished using the time diary, with the additional question, "[w] ho else was there but not directly involved in the activity?" Id.

${ }^{103} \mathrm{Id}$. at 220. The researchers analyzed thirteen activities: "going to the store; washing or folding clothes; doing dishes; cleaning house; preparing food; looking at books or reading stories; doing arts and crafts; talking about the family; working on homework; building or repairing something; playing computer or video games; playing a board game, card game, or puzzle; and playing sports or outdoor activities.” These questions were only asked with respect to children three years and older, with the result that the sample sizes are lowest for this variable. $I d$.

${ }^{104} \mathrm{Id}$. The study measured warmth by the father's responses to six items: "how often in the past month the father hugged each child, expressed his love, spent time with child, joked or played with child, talked with child, and told child he appreciated what he or she did." Id.

${ }^{105} \mathrm{Id}$. at 213 ("Biology explains less of father involvement than anticipated once differences between fathers are controlled.").

${ }^{106} \mathrm{Id}$. at 223. Both findings were significant at a high level of confidence, with $\mathrm{p}<.001$.

${ }^{107} \mathrm{Id}$. at 223 \& tbl.3 (reporting significance levels for the stepfather finding of $\mathrm{p}<.05$ and for the finding with respect to mother's cohabitants $\mathrm{p}<.001)$. Hofferth and Anderson surmised that these differences exist between biological and stepfathers because stepchildren may be receiving some or all of that time and attention from a nonresidential biological father, which "makes up for part of the shortfall with residential stepfathers." Id. at 223.

${ }^{108} \mathrm{Id}$. at $224 \&$ tbl.3. Both findings were significant at a high level of confidence, with $\mathrm{p}<.05$. 
whom they lived. Self-reports of warmth for married biological fathers, 5.10, were significantly greater than for stepfathers and mother's cohabitants, 4.36 and 3.69, respectively. ${ }^{109}$ Clearly, married biological fathers may be investing in their children more heavily than nonbiological fathers for reasons that have nothing to do with biology, but reflect instead wealth, educational levels, or other sociodemographic differences between these groups of men. ${ }^{110}$ To evaluate whether these sociodemographic differences accounted for the differences in investment, Hofferth and Anderson controlled for race, father's age, child's gender and age, number of children, percentage of months lived with the father, father's work hours per week and earnings, and whether the father paid child support for children outside the house. ${ }^{11}$

The increased investment in biological children persisted after controlling for socioeconomic factors. Specifically, nonbiological fathers spent over five hours less a week on average with their children than married biological fathers. ${ }^{112}$ Differences persisted for the second factor (hours available) only for stepfathers, who were available to the children 4.63 fewer hours than married biological fathers, ${ }^{113}$ while stepfathers and mother's cohabitants performed significantly fewer activities with a child than married, biological fathers, 4.35 fewer and 5.79 fewer, respectively. ${ }^{114}$

When it came to warmth, significant differences emerged for mother's cohabitants but not for stepfathers. Mother's cohabitants rated themselves less warm toward their children than married biological fathers did; stepfathers also reported lower warmth scores, although the difference was not statistically significant. ${ }^{115}$

Hofferth and Anderson concluded that, "consistent with evolutionary theory," biology affects a father's level of engagement. ${ }^{116}$ They concluded further that "fathers will not invest as much cognitively or emotionally in nonbiological as in biological offspring." "117 They cite several reasons for this difference: ${ }^{118}$ (1) that, particularly with regard to stepfathers, expectations are that they will be less involved with children, (2) that, particularly with regard to boyfriends, "parental" behavior toward their partner's child is "so new that norms have not developed to guide nonmarital partners in parenting children,"119 and (3) that men choosing to enter stepparent relationships may be positively or negatively selected depending on their motivation for becoming a de facto parent. ${ }^{120}$ That is, Hofferth and Anderson suggest that nonbiological fathers make investments in children but they do so in part because it gains them favor with the child's mother, or "reproductive access." 121 Thus, the benefits gained by children living with nonbiological fathers may recede or disappear once the relationship between the child's mother and her partner ends. Therefore, Hofferth

${ }^{109} \mathrm{Id}$. at 223, tbl.3. Both findings were significant at a high level of confidence, with $\mathrm{p}<.001$.

${ }^{110}$ See generally Wilson, supra note 89, at 854 (discussing differences in wealth, educational attainment, mobility, and other characteristics between married, two biological parent families and families in which a child lives with only one biological parent).

${ }^{111}$ Hofferth \& Anderson, supra note 85, at 224, 225 tbl.5.

112 Id. at 224, 225 tbl.5 (reporting that stepfathers spent 4.79 hours fewer per month engaged with their child than married biological fathers, $\mathrm{p}<.01$, while mother's cohabitants spent 3.60 hours fewer, $\mathrm{p}<.05$ ).

${ }^{113} I d$. at tbl.5 ( $\left.\mathrm{p}<.01\right)$. Mother's cohabitants were available for slightly more hours every month than married biological fathers, 0.80 , but the increase was not statistically significant.

${ }^{114} \mathrm{Id}$. at tbl.5 (reporting $\mathrm{p}$ values for both findings as $\mathrm{p}<.001$ ).

${ }^{115} \mathrm{Id}$. (reporting that mother's cohabitants rated themselves as less warm, -1.16 , with a significance value of $\mathrm{p}<.01$; while stepfathers also rated themselves as less warm, -0.38 , but this was not statistically significant).

${ }^{116}$ Hofferth \& Anderson, supra note 85, at $224 . \quad 117$ Id. at 229.

${ }^{118} \mathrm{Id}$. at 229-30. ${ }^{119} \mathrm{Id}$.

${ }^{120} \mathrm{Id}$. at 230.

${ }^{121}$ Id. at 215. 
and Anderson would predict that even if nonbiological fathers perform well in ongoing relationships, their performance may not be as strong when that relationship breaks up. ${ }^{122}$

In sum, these studies suggest that biology produces real differences in investment and outcomes for children. Because the studies used different data sets and comparison groups to isolate the impact of biology, the differences they uncover are surely more than statistical blips. Certainly, selection effects may explain the results in any correlational study. ${ }^{123}$ Nonetheless, these studies further an emerging literature on nonbiological caretakers that suggests that, as a group, the gains children realize from living with nongenetic caretakers may not be as great as we would otherwise suppose, and may represent only modest welfare increases over living alone with their mothers.

Some may see this decreased investment by nongenetic caretakers as irrelevant since only adults who meet the equal caretaking criterion qualify under the ALI's standard. Nonetheless, the drafters have not shown that performing equal caretaking functions during an intact relationship necessarily predicts the types of investments after break-up that warrant parental rights.

The differential investment by biological and nonbiological parents is important for another reason as well. The ALI assumes a child will be made better off by any time spent with the Ex Live-In Partner. Like the bundle of sticks that represents one's rights in property, such as the ability to exclude a person from private property, taking a stick from the legal parent's parenting bundle diminishes it. Here, giving time to an Ex Live-In Partner necessarily reduces the time that the biological mother can spend with the child. We should do this as a matter of policy only if we believe that the value of time spent with the Ex Live-In Partner exceeds the value of time spent with the child's mother, or if we believe that the child would get more out of that time if spent with the Ex Live-In Partner, or if spending time with an Ex Live-In Partner is costless and does not detract from the legal parent's time. It is far from clear that any of these assumptions are warranted.

More fundamentally, these studies examine children's welfare and the paternal investments that occur during the adults' intact relationship when, as many commentators have urged, "[i]nvestment in their partner's child may be an important relationship strategy for cohabiting men who wish to have their own children." 124 The ALI proposes to extend parental rights to these nonbiological fathers in the aftermath of failed relationships, a proposal that may actually produce seriously detrimental consequences for some children, as the next part explains.

\section{Evidence of Negative Repercussions to Some Children}

This part examines the impact of various features of de facto parents, as they are envisioned by the drafters, on a child's risk of physical abuse and sexual violence. It explains that a significant risk of sexual abuse arises in part when unrelated men, not present in a child's life from birth or shortly thereafter, have unsupervised access to a child without the moderating presence of the child's mother.

\footnotetext{
${ }^{122}$ Although the PrinCiples lump stepparents and unmarried live-in partners together, whether a mother and her partner choose to marry matters greatly to the level of investment that he makes in her child. Manning and Lamb and Hofferth and Anderson found "marriage advantages" for marital children over nonmarital children. See generally Wilson, supra note 89.

${ }^{123}$ See Wilson, supra note $90 . \quad{ }^{124}$ Hofferth \& Anderson, supra note 85, at 215.
} 


\section{A. Risk of Sexual Victimization by Ex Live-In Partners}

A child's exposure to unrelated men in her home plays a crucial role in determining her vulnerability to sexual victimization. Virtually every study of child sexual abuse reports that girls living with stepfathers are at high risk, ${ }^{125}$ leading one researcher to conclude that the presence of a stepfather is " $[t]$ he family feature whose risk has been most dramatically demonstrated." 126 While these studies differ in scope and the strength of their findings, they agree on one essential: the addition of an unrelated male "to a girl's family causes her vulnerability to skyrocket." 127

In one long-term study, researchers in New Zealand found that children reporting childhood sexual abuse were more likely to live with a stepparent before the age of fifteen. ${ }^{128}$ Of those children experiencing intercourse, nearly half (45.4 percent) were raised in a stepparent household. ${ }^{129}$ Similarly, Diana Russell found in a community survey of 933

${ }^{125}$ Hilda Parker \& Seymour Parker, Father-Daughter Sexual Abuse: An Emerging Perspective, 56 Ам. J. ОвтноручсніATRY 531, 541 (1986).

It is not immediately apparent why researchers have found a heightened risk of sexual abuse to girls in nontraditional families, but not for boys. See, e.g., David Finkelhor et al., Sexual Abuse in a National Survey of Adult Men and Women: Prevalence, Characteristics, and Risk Factors, 14 Child Abuse \& Neglect 19, 24-25 tbl.7 (1990) ("It would seem that almost any long-term disruption of the natural parent situation is risky for girls but not so for boys.") (emphasis added); Jean Giles-Sims, Current Knowledge About Child Abuse in Stepfamilies, 26 Marriage \& FAM. Rev. 215, 227 (1997) ("In summary, most studies of child abuse in stepfamilies indicate higher risks to children, particularly for sexual abuse of girls."). Because the heightened risk of abuse stems, in part, from abuse by Ex Live-In Partner, a disproportionate impact on girls should be expected. Ninety-nine percent of sexual abuse by a parent is perpetrated by fathers or father-substitutes, with the vast majority of these acts directed toward female children. Rebecca M. Bolen, Child Sexual Abuse: Its Scope and Our Failure 120 (2001).

This is not to say that boys are immune from sexual violations at the hands of their mother's partner. ANDREA J. Sedlak \& Diane D. Broadhurst, U.S. Dep't of Health \& Human Services, Third National Incidence Study of Child Abuse and Neglect: Final Report 5 at 6-5, 6-6 tbl.6-2 (1996) (reporting in a 1993 congressionallymandated study of 5,600 professionals in 842 agencies serving forty-two counties that one-fourth ( 25 percent) of sexually abused girls and boys were victimized by a parent substitute - defined to include in-home adoptive parents and stepparents, as well as parents' paramours). Moreover, as note 19 supra explains, the costs for boys of residing with unrelated males often takes the form of child homicide and punishing physical abuse and neglect.

${ }^{126}$ David Finkelhor, Epidemiological Factors in the Clinical Identification of Child Sexual Abuse, 17 CHILd Abuse \& NegLeCt 67, 68 (1993).

127 David Finkelhor, Sexually Victimized Children 122 (1979) [hereinafter Finkelhor, Sexually Victimized Children] (making the observation about stepfathers); see also Joseph H. Beitchman et al., A Review of the ShortTerm Effects of Child Sexual Abuse, 15 CHILd ABuse \& NegleCt 537, 550 (1991) (observing in a review of forty-two separate publications that "[t]he majority of children who were sexually abused.... appeared to have come from single or reconstituted families"); Jocelyn Brown et al., A Longitudinal Analysis of Risk Factors for Child Maltreatment: Findings of a 17-Year Prospective Study of Officially Recorded and Self-Reported Child Abuse and Neglect, 22 CHILD Abuse \& Neglect 1065, 1074 (1998) (finding in a longitudinal study of 644 families in upstate New York between 1975 and 1992 that disruption of relationships with biological parents and living in the presence of a stepfather increased girls' risk of sexual abuse); David M. Fergusson et al., Childhood Sexual Abuse, Adolescent Sexual Behaviors and Sexual Revictimization, 21 Child Abuse \& Neglect 789, 797 (1997) (finding in a longitudinal study of 520 New Zealand born young women that child sexual abuse was associated with living with a stepparent before the age of fifteen); David Finkelhor \& Larry Baron, High-Risk Children, in A Sourcebook on Children Sexual Abuse 60, 79 (David Finkelhor ed., 1986) ("The strongest and most consistent associations across the studies concerned the parents of abused children.... Girls who lived with stepfathers were also at increased risk for abuse."); John M. Leventhal, Epidemiology of Sexual Abuse of Children: Old Problems, New Directions, 22 Child Abuse \& Neglect 481,488 (1998) ("Studies have indicated that ... girls living with step-fathers are at an increased risk compared to girls living with biological fathers....").

${ }^{128}$ David M. Fergusson et al., Childhood Sexual Abuse and Psychiatric Disorder in Young Adulthood: I. Prevalence of Sexual Abuse and Factors Associated with Sexual Abuse, 35 J. Am. Acad. Child Adolescent Psychiatry 1355, 1359 tbl.2 (1996) (reporting results of a longitudinal study of 1,265 children born in Christchurch, New Zealand, who were studied from birth until the age of eighteen).

${ }^{129}$ See id. at 1358 tbl.1, 1359 tbl.2. 
women in San Francisco that one in six stepdaughters growing up with a stepfather was sexually abused, making these girls over seven times more likely to be sexually victimized than girls living with both biological parents. ${ }^{130}$ Indeed, of forty risk factors tested for association with child sexual abuse in an early study, the presence of a stepfather "remained the strongest correlate of victimization, even when all other variables were statistically controlled." 131

Stepfathers and mother's cohabitants also represent a greater proportion of abusers than their incidence in the general population, suggesting that they are more likely to abuse girls in their care than are biological fathers. In their study of children molested by caretakers, Leslie Margolin and John Craft posited that stepfathers should account for 10.6 percent of all father abuse "[b]ased on the percent of children cared for by nonbiologically related fathers." 132 In fact, "they accounted for [41 percent] of all sexual abuse, or almost [four] times what would be expected based on the percent of children cared for by nonbiologically related fathers." ${ }^{\prime 33}$ Multiple studies in North America have found similar results. ${ }^{134}$ This overrepresentation appears to be an international phenomenon, consistent across

${ }^{130}$ Russell, supra note 72, at 255 (1986) (reporting in a study of 930 women in the San Francisco area, that $2 \%$ of respondents reared by biological fathers were sexually abused, while "at least [17\%] of the women in our sample who were reared by a stepfather were sexually abused by him before the age of fourteen"); $c f$. Parker \& Parker, supra note 125, at 541 (finding risk of abuse associated with stepfather status to be almost twice as high as for natural fathers). Significantly, the risk of sexual assault by father-substitutes "who are around for short[er] lengths of time... may be considerably higher." Russell, supra, at 268.

131 David Finkelhor, Child Sexual Abuse: New Theory and Research 25 (1984).

${ }^{132}$ Margolin \& Craft, supra note 125, at $452 . \quad{ }^{133} \mathrm{Id}$.

${ }^{134}$ E.g., U.S. Dep't of Health \& Human Services, Study Findings: National Study of the Incidence and Severity of Child Abuse and Neglect 31 tbl.5-5 (1981) (finding in a stratified random sample of child protective services agencies in twenty-six counties within ten states that stepfathers were involved in 30 percent of the reported sexual abuse cases, while biological fathers were involved in 28 percent of the cases); Hendrika B. Cantwell, Sexual Abuse of Children in Denver, 1979: Reviewed with Implications for Pediatric Intervention and Possible Prevention, 5 Child Abuse \& Neglect 75, 77 tbl.1 (1981) (finding in a study of 226 substantiated cases of child sexual abuse in Denver, Colorado during 1979 that 27.5 percent of children were sexually victimized by a surrogate father, compared to 26.5 percent who were abused by their natural father); Gruber \& Jones, supra note 127, at 21-22 (finding in a study of delinquent adolescent females that living with a stepfather or foster father "significantly discriminated the victim and nonvictim groups," with 85 percent of sexual abuse victims coming from single or stepparent families compared to 47 percent of psychiatric controls); Robert Pierce \& Lois Hauck Pierce, The Sexually Abused Child: A Comparison of Male and Female Victims, 9 Child Abuse \& Neglect 191, 191-93, 194 tbl.2 (1985) (ascertaining from a review of 180 substantiated cases of sexual abuse reported to a child abuse hotline between 1976 and 1979 that $41 \%$ of the perpetrators against girls were the child's natural father, while 23 percent were the child's stepfather); Edward Sagarin, Incest: Problems of Definition and Frequency, 12 J. SEx REs. 126, 13334 (1977) (concluding from a study of 75 cases of heterosexual incest involving 32 stepfathers and 34 biological fathers, that "it appears that the likelihood of a stepfather-stepdaughter relationship is far greater than [a] fatherdaughter [relationship]" because the "number of households in which there is a stepfather and stepdaughter is surely many times lesser than those in which there is a father and daughter"); $c f$. Mary De Young, The SexuAL Victimization of Children 3, 16 (1982) (finding in a study of eighty incest victims that 39 percent of the incest offenders were stepfathers, leading the author to conclude "that the introduction of a stepfather into a family does increase the possibility that the stepdaughter will become the victim of incest"); Mark D. Everson et al., Maternal Support Following Disclosure of Incest, 59 Am. J. Orthopsychiatry 198, 198-99 (1989) (noting in a sample of eighty eight children recruited from eleven county social service agencies in North Carolina over a twenty-eight month period to study the effects of maternal support that 30 percent of the perpetrators were biological fathers, 41 percent were stepfathers, and 17 percent were mothers' boyfriends); Elizabeth A. Sirles \& Pamela J. Franke, Factors Influencing Mothers' Reactions to Intrafamily Sexual Abuse, 13 Child Abuse \& Neglect 131, 133 \& tbl.1 (1989) (finding in a maternal support study of 193 incest victims receiving counseling services in St. Louis, Missouri, that sixty-four children were molested by their father, with an equal number abused by a stepfather or a mother's live-in partner). 
cultures. ${ }^{135}$ A study of child abuse registers in the United Kingdom found that 46 percent of paternal offenders were nonbirth fathers, compared to 54 percent who were birth fathers. ${ }^{136}$ Given the fact that during the study time frame only 4 percent of British children resided with nonbirth fathers, father-substitutes appear "substantially over-represented" among perpetrators. ${ }^{137}$ As one researcher concluded, "a stepfather was five times more likely to sexually victimize his stepdaughter than was a genetic father."138

In more than one study, stepfathers actually outnumbered natural fathers as abusers, a telling result given the disproportionately greater number of biological fathers during the study time frames. ${ }^{139}$ Christopher Bagley and Kathleen King estimate that "as many

${ }^{135}$ Michael Gordon \& Susan J. Creighton, Natal and Non-natal Fathers as Sexual Abusers in the United Kingdom: A Comparative Analysis, 50 J. Marriage \& FAM. 99, 100, 101, 104 (1988) (finding in a review of data collected by the National Society for the Prevention of Cruelty to Children that stepfathers and father substitutes "were disproportionately represented among perpetrators"); Russell P. Dobash et al., Child Sexual Abusers: Recognition and Response, in Child Abuse and Child Abusers: Protection and Prevention 113, 114-15, 124 fig.6.6, 126 (Lorraine Waterhouse ed., 1993) (finding in a study of fifty-three known perpetrators of child abuse in Scotland that 12.59 percent of child victims lived with their mother and her cohabitant, while 21.16 percent lived with their mother and a stepfather, leading the authors to conclude that "children living with step-fathers and [unrelated] male cohabitees appear to be much more at risk of sexual abuse than children living with both their natural parents"); Patricia J. Mrazek et al., Sexual Abuse of Children in the United Kingdom, 7 Child Abuse \& Neglect 147, 150 (1983) (noting in a survey of 1,599 family doctors, police surgeons, pediatricians, and child psychiatrists in the United Kingdom that " $[\mathrm{w}]$ ithin the family, the natural father was most likely $(48 \%)$ to be the perpetrator, with stepparents the next most common (28\%)"); Heikki Sariola \& Antti Uutela, The Prevalence and Context of Incest Abuse in Finland, 20 Child Abuse \& Neglect 843, 846 (1996) (reporting that 3.7 percent of Finnish girls living with a stepfather reported being sexually abused by him, making stepfather-daughter abuse 15 times more common than father-daughter incest); S. N. Madu \& K. Peltzer, Risk Factors and Child Sexual Abuse Among Secondary School Students in the Northern Province (South Africa), 24 Child Abuse \& Neglect 259, 260, 266 (2000) (reporting that having a stepparent in the family during childhood significantly predicted risk of child sexual abuse); S. Krugman et al., Sexual Abuse and Corporal Punishment During Childhood: A Pilot Retrospective Survey of University Students in Costa Rica, 90 Pediatrics 157, 157-58 (1992) (finding in a study of 497 Costa Rican university students that a stepfather caused 6.3 percent of the female abuse experiences, while natural fathers caused 3.2 percent); R. Chen, Risk Factors for Sexual Abuse Among College Students in Taiwan, 11 J. Interpersonal Violence 79, 88, 91 (1996) (discovering that those Taiwanese respondents "who did not live with both parents before college faced a higher risk [of childhood sexual abuse] than those who lived with both parents"); see also David Finkelhor, The International Epidemiology of Child Sexual Abuse, 18 Child Abuse \& Neglect 409, 412 (1994) (reviewing international studies of child sexual abuse and debunking the notion that "the problem is more severe in North America").

${ }^{136}$ Gordon \& Creighton, supra note 135, at 99, 100, 101, 104 (reviewing data collected by the National Society for the Prevention of Cruelty to Children).

137 Id. See also David Thorpe, Evaluating Child Protection 1, 84, 115 (1994) (finding in a study of social service referrals in the UK and western Australia that parents were responsible for 27.7 percent of the sexual abuse cases; in contrast, stepparents and de facto parents accounted for 24.8 percent of cases); Mrazek et al., supra note 135, at 150 (noting in a survey of 1,599 family doctors, police surgeons, pediatricians, and child psychiatrists in the UK that "[w] ithin the family, the natural father was most likely (48\%) to be the perpetrator, with stepparents the next most common (28\%)"); Susan J. Creighton \& Neil Russell, Voices From Childhood: A Survey of Childhood Experiences and Attitudes to Child Rearing Among Adults in the United Kingdom 45 tbl.14 (1995) (reporting that 8 percent of respondents in England, Scotland, and Wales were sexually abused by their fathers, while 7 percent were victimized by a stepfather); Dobash et al, supra note 135, at 120 (finding in an analysis of 501 sexual abuse case files taken from Scottish police and child protection agencies that 23 percent of identified abusers were the child's natural father while 23 percent were the victim's stepfather or father substitute).

138 David Finkelhor, Risk Factors in the Sexual Victimization of Children, 4 Child Abuse \& Neglect 265, 269 (1980) (reporting results of a study of college undergraduates).

139 Vincent De Francis, Protecting the Child Victim of Sex Crimes Committed by Adults: Final Report 69 (1969) (finding in a study of 250 sexual abuse cases that the natural father committed the offense in 13 percent of the cases, whereas in 14 percent of cases the offense was committed by a stepfather or by the man with whom the child's mother was living); GraY, supra note 134, at 85 fig.4.10 (noting in a study of all cases of molestation filed in eight jurisdictions that 23.3 percent of accused perpetrators were stepfathers and boyfriends, while biological fathers accounted for 13.4 percent); Giles-Sims \& Finkelhor, supra note 134, at 408 tbl.1 (reporting that 30 percent 
as one in four stepfathers may sexually abuse the female children to whom they have access." 140

Rebecca Bolen's research on multiple risk factors solidifies the connection between sexual victimization and living with unrelated men. ${ }^{141}$ She used statistical tools to distinguish the effect of living without both natural parents from other aspects of household composition. ${ }^{142}$ When all other variables were held constant, she found "children living with males in the household after separation [of their parents] were more than seven times more likely to be abused" than "children living with only females after separation." 143 In hard numbers, "over half of these children were sexually abused." 144

Bolen's findings suggest that the heightened risk to girls does not result from the breakup of a traditional nuclear family itself, ${ }^{145}$ but "[i] nstead, living with a male in the household after separation... appeared to be the more important predictor." 146 As Bolen observes, "for children living with a male in the household, rates of abuse appeared to be better explained by (a) living with a stepfather or (b) being separated from one's natural mother." 147

\section{B. The Attractiveness of Single Mothers to Sex Offenders Who Target Children}

That sex offenders might use adult relationships in order to gain access to child victims is firmly established. One sex offender's "guide" to molesting children begins with finding

of abusers in the study were stepfathers, outnumbering natural father abusers, who constituted 28 percent of the abusers).

${ }^{140}$ Christopher Bagley \& Kathleen King, Child Sexual Abuse: The Search for Healing 75-6 (1990). The risk of abuse to girls from an Ex Live-In Partner is even greater than these comparisons suggest because these girls "are also more likely than other girls to be victimized by other men." FinKELHOR, supra note 131, at 25. For example, stepdaughters are five times more likely to be abused by a friend of their parents than are girls in traditional nuclear families. $I d$. Thus, stepfathers "are associated with sexual victimization not just because they themselves take advantage of a girl, but because they increase the likelihood of a nonfamily member also doing so." FINKELHOR, Sexually Victimized Children, supra note 127, at 130. See also Bagley \& King, supra, at 91 (citing study finding that girls separated from one parent "were also at risk for sexual victimization by more than one adult"). Because the risk of sexual abuse is cumulative, one researcher found that "[v]irtually half the girls with stepfathers were victimized by someone." Finkelhor, supra note 131, at 25.

${ }^{141}$ See Rebecca M. Bolen, Predicting Risk to Be Sexually Abused: A Comparison of Logistic Regression to Event History Analysis, 3 Child Maltreatment 157 (1998).

${ }^{142} \mathrm{Id}$. (performing multivariate analyses of data from Diana Russell's survey of 933 adult women in the San Francisco area).

${ }^{143} \mathrm{Id}$.

${ }^{144} \mathrm{Id}$. at 163 (reporting that 53 percent were sexually abused).

${ }^{145}$ Some may see the risks to children in fractured and blended families as a deficit of their family form (i.e., whether they have two parents). These statistics would not support such an inference - an intact family does not immunize a child from sexual exploitation. E.g., Finkelhor, supra note 126, at 68 ("[T] $]$ he presence of both natural parents is certainly not an indicator of low risk in any absolute sense."); P. E. Mullen et al., The Long-Term Impact of the Physical, Emotional, and Sexual Abuse of Children: A Community Study, 20 Child Abuse \& Neglect 7, 18 (1996) (conceding that "[i]ntact families do not guarantee stability"). See generally Wilson, supra note 20.

${ }^{146}$ Bolen, supra note 141 , at 167.

${ }^{147} \mathrm{Id}$. at 166. While "the addition of a stepfather to a girl's family causes her vulnerability to skyrocket," FinKelHor, SeXUAlly Victimized Children, supra note 127, at 122, it is overly simplistic to assume that the mother's remarriage or cohabitation is a necessary predicate to victimization. A girl's long-term separation from her father - a risk factor "strongly associated" with childhood victimization - is sometimes, but not always, followed by the introduction of unrelated males into the household. BAGLEY \& KING, supra note 140, at 91 (reporting results from several research studies). 
"some way to get a child living with you." 148 Anna Salter's interviews of sex offenders include a particularly chilling account by a sex offender who deliberately dated women in order to rape their children. ${ }^{149}$ These men are not alone in taking this approach. Asked about their modus operandi in selecting victims, seventy-two incarcerated child molesters indicated they deliberately targeted "passive, quiet, troubled, lonely children from broken homes," since these characteristics indicate a child's vulnerability to the offender's advances. ${ }^{150}$

As one child molester explains, by selecting a child "who doesn't have a happy home life," it is "easier to groom them and to gain their confidence." 151 This should come as no surprise. At least for those children who have experienced divorce, the emotional void created by the loss of a parent sometimes opens the child up to the abuser's predations, ${ }^{152}$ making them less able to say "no" to unwanted sexual advances. ${ }^{153}$ Offenders then simply exploit "a child's normal need to feel loved, valued and cared for." ${ }^{154}$ Family fragmentation offers offenders a second advantage as well: it often isolates the child from social supports that existed before the divorce. ${ }^{155}$

This heightened vulnerability may also stem, in part, from a lack of supervision, as single and separated parents navigate the taxing process of parenting alone and rebuilding their lives. ${ }^{156}$ Many custodial and single mothers must work outside the home to support their family, diminishing the opportunity to supervise their children. ${ }^{157}$ As Judith Wallerstein

148 See Jon R. Conte et al., What Sexual Offenders Tell Us About Prevention Strategies, 13 Child Abuse \& Neglect 293, 298 (1989) (asking sex offenders to describe their methods).

${ }^{149}$ Videotape: Truth, Lies, and Sex Offenders (Anna C. Salter 1996) (on file with author).

${ }^{150}$ Lee Eric Budin \& Charles Felzen Johnson, Sex Abuse Prevention Programs: Offenders' Attitudes About Their Efficacy, 13 Child Abuse \& Neglect 77, 79, 84 (1989). Similarly, one study of twenty adult sexual offenders in a Seattle, Washington, treatment program found that offenders selected victims based on the child's vulnerability, with vulnerability "defined both in terms of children's status (for example living in a divorced home or being young) and in terms of emotional or psychological state (for example a needy child, a depressed or unhappy child)." Conte et al., supra note 148 , at 293 . For a particularly chilling account by a sex offender who deliberately dated women in order to rape their children, see Videotape: Truth, Lies, and Sex Offenders (Anna C. Salter, 1996) (on file with author).

${ }^{151}$ Conte et al., supra note 148, at 298. Children in single and reconstituted families are a subset of a broader group of children who are more vulnerable to sexual abuse as a result of family circumstances. For instance, children who live in households marked by domestic violence, drug and alcohol abuse, mental health issues, and other problems all face elevated risks of sexual abuse. See Bolen, supra note 125, at 136 tbl.81 (cataloging studies finding parental alcohol and drug abuse as a risk factor for child sexual abuse); Margaret F. Brinig, Choosing the Lesser Evil: Comments on Besharov's "Child Abuse Realities," 8 VA. J. Soc. PoL'Y \& L. 205 (2000) (discussing empirical evidence showing a relationship between parental substance abuse or domestic violence and the abuse of children).

${ }^{152}$ Lucy Berliner \& Jon R. Conte, The Process of Victimization: The Victims' Perspective, 14 Child Abuse \& Neglect 29, 35-36, 38 (1990) (finding in interviews of twenty-three child victims of sexual abuse that "[i]n many cases the sexual abuse relationship filled a significant deficit in the child's life.... The children were troubled and/or their parents were not resources for them.").

${ }^{153}$ See, e.g., Conte et al., supra note 148, at 299 (describing ways in which sexual predators "manipulate... [a child's] vulnerability as a means of gaining sexual access").

${ }^{154}$ Berliner \& Conte, supra note 152, at 35-36, 38 (interviewing twenty-three child victims of sexual abuse).

${ }^{155}$ See, e.g, Sue Boney-McCoy \& David Finkelhor, Is Youth Victimization Related to Trauma Symptoms and Depression After Controlling for Prior Symptoms and Family Relationships?: A Longitudinal, Prospective Study, 64 J. Consulting \& Clinical Psychol. 1406, 1415 (1996) (finding in a national telephone survey of children that a child's prior symptoms of depression increased a child's risk of later sexual victimization, "perhaps because anxious children are less able to protect themselves and may present easier targets for victimization"); Budin \& Johnson, supra note 150, at 77, 79 (reporting that child molesters deliberately selected victims who had "no male figures in their lives").

${ }^{156}$ Finkelhor, Sexually Victimized Children, supra note 127, at 124 (speculating that the custodial parent's new relationship may take "time and energy and actually mean less supervision of the child than previously").

157 See, e.g., Saul Hoffman \& Greg Duncan, What Are the Economic Consequences of Divorce?, 25 Demography 641, 644 (1988) (showing a decline in economic status of about one-third for women and children after divorce); Ross Finnie, Women, Men, and the Economic Consequences of Divorce: Evidence from Canadian Longitudinal Data, 30 
has explained, "[i]t's not that parents love their children less or worry less about them [after divorce, but rather that] they are fully engaged in rebuilding their own lives - economically, socially and sexually." 158

\section{Risk of Sexual Abuse when a Child's Mother is Absent}

The ALI's efforts to secure continuing contact between children and Ex Live-In Partners after the breakup of the adult relationship is problematic for other reasons, as well. These men will typically have access to the children outside the presence of their mothers. ${ }^{159}$ The mere absence of a girl's mother heightens her risk for sexual exploitation. ${ }^{160}$ For instance, researchers have compared girls who lived without their mother before the age of sixteen to those who remained with their mother throughout childhood. The sexual vulnerability of the estranged girls was nearly 200 percent greater than that of other girls, leading one researcher to conclude that "missing a mother is the most damaging kind of disruption." 161

This pattern of a girl's heightened vulnerability in mother-absent households is repeated in multiple studies. ${ }^{162}$ In their investigation of father-daughter incest, Judith Herman and Lisa Hirschman found that risk of incest was particularly acute in families in which mothers were absent from the home due to hospitalization or other reasons. ${ }^{163}$ Another study found that "[f] or women abused by someone outside of the family, the significant predictors [included] ... mother's death [] and having an alcoholic mother." 64 The authors speculate that a mother's absence, in the form of her death or mental illness, "may place the child at risk of neglect that involves a lack of supervision." 165 In one of the few longitudinal studies

Canadian Rev. Soc. \& Anthropology 205, 206 (1993) (reporting that the income-to-needs ratio for women drops just over 40 percent in the first year of divorce, followed by a moderate rise in subsequent years); Richard R. Peterson, A Re-Evaluation of the Economic Consequences of Divorce, 61 Am. Soc. Rev. 528, 528 (1996) (noting one study of women in Los Angeles that estimated that women's standard of living declined 73 percent after divorce).

${ }^{158}$ WALlerstein ET AL., supra note 6, at xxix.

159 See Finkelhor, Sexually Victimized Children, supra note 127, at 124 (noting that for many mothers divorce necessitates working outside the home to support their families, diminishing the time and attention previously showered on their children); WALLERSTEIN ET AL., supra note 6, at xxix (that the presence of a new man in a mother's life takes up time and energy previously shown to the children).

${ }^{160}$ Most studies analyzing the "mother-absent" factor have examined situations in which the mother was absent for prolonged and sustained periods for time, due to health, mental illness, or death. The risk remains particularly acute in reconstituted families because the child's mother will be absent for certain periods of time and will rely on a nongenetic caretaker for supervision of the children, therefore magnifying the established baseline risk of having such an individual in the child's life by giving him access to that child outside her presence.

161 Finkelhor, Sexually Victimized Children, supra note 127, at 121.

162 See, e.g., Russell, supra note 72, at 363 (enumerating studies that have "shown that many mothers of incest victims are sick, absent, or in powerless or abusive situations themselves"); Alexander, supra note 127, at 185 (citing research documenting that maternal unavailability is among the "most significant predictors for increased risk for all kinds of sexual abuse"); Michael Gordon, The Family Environment of Sexual Abuse: A Comparison of Natal and Stepfather Abuse, 13 Child Abuse \& Neglect 121, 128 (1989) (noting that "a girl whose mother is absent or passive is more vulnerable to abuse than a girl whose mother is present and active”); Mullen et al., supra note 145, at 18 (concluding that "having a close and confiding relationship with the mother seemed to confer a degree of protection").

163 See Herman \& Hirschman, supra note 125, at 968. Herman and Hirschman found that " $[\mathrm{m}]$ others in the incestuous families were more often described as ill or disabled and were more often absent for some period of time." Id. Specifically, "[f]ifty percent of the women in the incest group but only [ 15 percent] of the comparison group reported that their mothers had been seriously ill.” Id. With regard to maternal absence, 38 percent of the women in the incest group reported separation from their mothers for some period of time during childhood, while none of the comparison group had been estranged from their mothers. $I d$.

164 Jillian Fleming et al., A Study of Potential Risk Factors for Sexual Abuse in Childhood, 21 Child Abuse \& Neglect 49, 50, 55 (1997) (enumerating factors possibly associated with childhood sexual abuse, including "living apart from their mother at some time during their childhood").

${ }^{165} \mathrm{Id}$. at 56. 
of a general population, David Fergusson and his colleagues followed 1,265 children from birth until the age of sixteen. ${ }^{166}$ They found that 66.5 percent of the victims of sexual abuse came from families that "experience[d] at least one change of parents before age 15," compared to 33.5 percent of children who did not experience abuse. ${ }^{167}$ The only national survey in the United States to examine risk factors for child sexual assault at the time found higher rates of abuse among women who reported living for some period of time without one of their biological parents. ${ }^{168}$ At least a dozen other studies confirm that sexual victimization occurs more often in disrupted families. ${ }^{169}$ Those studies estimating

${ }^{166}$ Fergusson, supra note 128, at 1356 (following a cohort of children born in Christchurch, New Zealand in 1977 and asking them at age eighteen to provide retrospective reports of molestation experiences during childhood). See, e.g., BAGLEY \& KING, supra note 140, at 90 ("It is not typical for sexual abuse to occur independently of other aspects of family dysfunction. It occurs with greater frequency in homes disrupted by parental absence or separation...”); Alexander, supra note 127, at 185 ("[C] ertain family characteristics are the most significant predictors for increased risk for all kinds of child sexual abuse, [including] absence of a biological parent.”); Christopher Bagley \& Richard Ramsey, Sexual Abuse in Childhood: Psychosocial Outcomes and Implications for Social Work Practice, in Social Work Practice in Sexual Problems 42 (James Gripton \& Mary Valentich eds., 1986) (stating that molestation "occurs with greater frequency in homes which are disrupted by the child's separation from one or both parents," but cautioning that "sexual abuse is not[,] in statistical terms, a direct function of family variables"); Brown et al., supra note 127, at 1075 (finding in a study of 644 families in upstate New York surveyed on four occasions between 1975 and 1992 that disruption in a child's relationship with her biological parent increases her risk of sexual abuse); Ann W. Burgess et al., Abused to Abuser: Antecedents of Socially Deviant Behaviors, 144 AM. J. PsychIATRY 1431, 1433 (1987) (finding in follow-up studies of two groups of adolescents who participated in sex rings as children, that 70 percent of adolescents who participated in the sex rings for more than one year were from single-parent families, compared to 47 percent of the adolescents who were involved for less than a year); Fergusson et al., supra note 127, at 797 (finding in a longitudinal study of 520 New Zealand-born children that "[y] oung women who reported [child sexual abuse] were more likely [than nonabused children] to have experienced at least one change of parents before the age of [fifteen]"); David Finkelhor, Current Information on the Scope and Nature of Child Sexual Abuse, Future of Child., Summer/Fall 1994, at 31, 48 ("In many studies ... children who lived for extended periods of time apart from one parent have been found to bear elevated risks for sexual abuse."); Finkelhor, supra note 126, at 68 (concluding that "[i]n general, children who are living without one or both of their natural parents are at greater risk for abuse"); Giles-Sims, supra note 125, at 218 (noting that the "sexual abuse literature is more consistent ... in finding that children not living with both natural parents run higher risks of child sexual abuse both from family members and others, but the exact magnitude of reported risk varies across studies"); Parker \& Parker, supra note 125, at 532 ("Reconstituted families, stepparent and broken families, with mother's male companions in the home, seem to be vulnerable."); Anne E. Stern et al., Self Esteem, Depression, Behaviour and Family Functioning in Sexually Abused Children, 36 J. Child. Psychol. \& Psychiatry \& Allied Disciplines 1077, 1080 \& 1081 tbl.1 (1995) (finding in a comparison of eighty-four sexually abused children and their families to nonabused controls that the abused group had more marital breakdown and change of parents than the nonabused group).

${ }^{167} I d$. at 1359 tbl.2. Fergusson reports, moreover, that 60 percent of children who experienced intercourse as part of the abuse experience had been exposed to parental divorce or separation. $I d$. However, in a regression analysis, investigators found that five factors - gender, marital conflict, parental attachment, parental overprotection, and parental alcoholism - were predictive of reported abuse. Id. at 1360 \& 1360 tbl.3.

${ }^{168}$ Finkelhor et al., supra note 125, at 24 (finding in a national survey of 2626 adult men and women that separation from a natural parent for a major portion of one's childhood is a risk factor for sexual victimization).

169 E.g., De Francis, supra note 139, at 50 (finding in a study of 250 sexual abuse cases that in 60 percent of the families, the children's natural father or natural mother was not in the home - "an extraordinary high incidence of broken homes"); Russell, supra note 72, at 103, 104 tbl.8-1 (revealing that "women who were reared by both of their biological or adoptive parents were the least likely to be incestuously abused"); S. KIRsON WEINBERG, INCEST BEHAVIOR 49 (1955) (finding in a study of 203 incest cases in the State of Illinois that 40.3 percent of the fathers were widowed or separated from their wives at the start of incestuous relationships with their daughters); Raymond M. Bergner et al., Finkelhor's Risk Factor Checklist: A Cross-Validation Study, 18 Child Abuse \& Neglect 331, 334 (1994). (finding that "separation from mother during some period" discriminated between abused and nonabused subjects in a study of 411 female college students); Bolen, supra note 141, at 157, 164 (finding in a multivariate analysis of Diana Russell's survey data on 933 adult women in the San Francisco area that "[r] espondents living with both natural parents prior to the age of fourteen had the lowest rates of abuse"); Finkelhor \& Baron, supra note 127, at 60, 73, 79 (noting the "impressive number of studies with positive findings on the question of parental absence" and concluding that "[t]he strongest and most consistent associations across the studies concerned the parents of abused children," and that "[g] irls who are victimized are... more likely to have lived without their 
the incidence of sexual abuse find that as many as half the girls in fractured families report sexual abuse as a child. ${ }^{170}$

Although we have scant research on the risks to girls in father-custody households, ${ }^{171}$ what is available underscores the significance of a mother's absence, both temporary and long term. One national survey in the United States found significantly elevated risk of molestation for girls following divorce, "particularly when living alone with [their] father." ${ }^{\prime 72}$ In that study, 50 percent of female children residing solely with their father reported sexual abuse by someone, although not necessarily their father. ${ }^{173}$ Similarly, a 1995 poll of parents about child maltreatment found an annual rate of child sexual abuse for boys and girls in single-father households equal to forty-six victims per one thousand children. ${ }^{174}$ In comparison, parents in two-parent households reported a rate of eleven victims per one thousand children. ${ }^{175}$

It is unclear how much weight should be given to the studies of mothers' absence since under the ALI's proposal, a child's legal parent would be presumptively entitled to half the custodial responsibility for a child. In one sense, the mother remains present

natural fathers"); Kenneth J. Gruber \& Robert J. Jones, Identifying Determinants of Risk of Sexual Victimization of Youth: A Multivariate Approach, 7 Child Abuse \& Neglect 17, 21 tbl. 2 1983) (discovering in a sample of delinquent adolescent females in Western North Carolina that victims of child sexual assault were less likely to be living with both natural parents - 15 percent of the abused children lived with both natural parents while 52 percent of nonabused children did so); Marcellina Mian et al., Review of 125 Children 6 Years of Age and Under Who Were Sexually Abused, 10 Child Abuse \& Neglect 223, 227 (1986) (finding that 67 percent of the victims of intrafamilial abuse came from families in which parents had separated or divorced, compared to 27 percent of the children abused by perpetrators outside of the family); Mullen et al., supra note 145, at 8-9, 18 (reporting, in a study of 2,250 randomly selected adult women in New Zealand, that sexual, physical, and emotional abuse "occurred more often in those from disturbed and disrupted home backgrounds"); Nancy D. Vogeltanz et al., Prevalence and Risk Factors for Childhood Sexual Abuse in Women: National Survey Findings, 23 Child Abuse \& Neglect 579, 586 (1999) (finding, after using statistical analysis to unravel the effects of multiple risk factors, that not living with both biological parents by the age of sixteen ranked among those factors "significantly associated with increased risk of [child sexual abuse]"); Patricia Y. Miller, Blaming the Victim of Child Molestation: An Empirical Analysis (1976) (unpublished Ph.D. dissertation, Northwestern University) (on file with author) (discovering that biological father's absence "directly influence[d] molestation" and constituted the "variable [with] the largest direct effects on... victimization"); $c f$. Kristin Anderson Moore et al., Nonvoluntary Sexual Activity Among Adolescents, 21 FAM. Plan. PersP. 110, 113 tbl.3 (1989) (ascertaining in a study of white female adolescents that having parents who are "separated, divorced or never-married" doubles the likelihood of sexual abuse, although the association was not significant when other factors were controlled).

${ }^{170}$ E.g., Finkelhor, Sexually Victimized Children, supra note 127, at 125 (discovering that 58 percent of the girls who at some time before the age of sixteen had lived without their mothers had been sexually victimized, three times the rate for the whole sample, making these girls "highly vulnerable to sexual victimization"); Bagley \& Ramsey, supra note 166, at 37 \& 38-39 tbl.1 (reporting that 53 percent of women separated from a parent during childhood reported sexual abuse).

${ }^{171}$ The absence until recently in child sexual abuse studies of "raised by father only" and "raised by father and stepmother" categories reflects the historical preference for maternal custody. See, e.g., Homer H. Clark, JR., The LaW of Domestic Relations in the United States $\$ 19-4$, at 803 (2d ed. 1988).

${ }^{172}$ Finkelhor et al., supra note 125, at 24-25, tbl.7. See also Giacomo Canepa \& Tullio Bandini, Incest and Family Dynamics: A Clinical Study, 3 InT'L J. L. \& Psychiatry 453, 459 (1980) (discussing the recurrence of several factors in nine case histories of father-daughter incest, with a stepmother's presence occurring in two of the nine case histories).

${ }^{173}$ See Finkelhor et al., supra note 125, at 25 tbl.7.

174 See Gallup Org., Disciplining Children in America: A Gallup Poll Report 16 (1995) (reporting results of poll of 1,000 parents); see also Desmond K. Runyan, Prevalence, Risk, Sensitivity, and Specificity: A Commentary on the Epidemiology of Child Sexual Abuse and the Development of a Research Agenda, 22 CHILd Abuse \& Neglect 493, 495 (1998) (observing that "[a]n obvious area of research is to sort out the additional risk [for male and female children of] being victimized in single parent households and why the rate is higher in male-headed households").

${ }^{175}$ Gallup Org., supra note 174 , at 16. 
because the child returns home after visits with the de facto parent. In another sense, however, the mother is absent for those periods when the child is in the custody of the de facto parent, away from the mother's watchful, discerning eyes. There are good reasons, moreover, to avoid contexts that permit illicit desires to gain ground and manifest themselves. Many abused children never disclose the abuse; many outwardly display no telltale symptoms. ${ }^{176}$ In fact, the abuse most likely to remain shrouded in secrecy often occurs at the hands of a father figure, ${ }^{177}$ while violations by father figures are among the most depraved. ${ }^{178}$

\section{Risks to Children Who Have Not Resided with an Adult from Infancy}

Children also face a disproportionate risk from adults who have not resided with them from infancy, whether those adults have a biological connection to the child or not. Child abuse researchers have always been perplexed by runaway rates of incest in Navy families, an obvious conundrum for those who believe that a biological tether insulates a child from sexual exploitation. In a comparison of paternal caretaking among 118 incestuous fathers and 116 closely matched nonincestuous fathers, Williams and Finkelhor found that incestuous fathers were significantly less likely to have been in the home or involved in child-care activities during the child's first three years of life. ${ }^{179}$ They concluded that involvement in non-bodily caretaking activities, like reading stories, during the first three to six years of a child's life serves to inhibit incest to the greatest degree. ${ }^{180}$ While early care giving inhibits incest, it does not do so by inhibiting sexual arousal. ${ }^{181}$ Rather, the inhibitory effect stems from the enhancement of parental impulses, developed when the child is very young, that allow the adult to view the child as his own. ${ }^{182}$ Thus, the Residency Requirement may be protective if residency were required during a child's infancy but is not a be-all-and-end-all itself.

While high involvement in care giving during a child's early years is protective against incest, "being the sole care-giver for a daughter for at least 30 consecutive days was [also]

\footnotetext{
${ }^{176}$ Mian et al. found that the rate of purposeful (as opposed to unintentional) disclosure by the child decreased significantly when the perpetrator was intrafamilial. Mian et al., supra note 169, at 226 tbl.5. In fact, a greater proportion of children victimized by family never tell (17.7\%) than occurs with children who are the victims of extrafamilial abuse (10.9\%). See Donald G. Fischer \& Wendy L. McDonald, Characteristics of Intrafamilial and Extrafamilial Child Sexual Abuse, 22 Child Abuse \& Neglect 915, 926 (1998).

Physical manifestations one might expect are also frequently absent. A third of sexually abused children have no apparent symptoms. K. A. Kendall-Tackett et al., Impact of Sexual Abuse on Children: A Review and Synthesis of Recent Empirical Studies, 113 Psychol. Bull. 164, 167 (1993). Roughly half fail to display the classic, most characteristic symptom of child sexual abuse: "sexualized" behavior. Id.

177 "The more severe cases [are] the ones most likely to remain secret." RusselL, supra note 72, at 373 . Russell reports that in 72 percent of the cases in which mothers were unaware of the abuse, more severe abuse had occurred. Id. at 372.

${ }^{178}$ Abuse by father-figures occurs with greater frequency, over a longer time frame, and is more likely to include penetration, physical contact, force, and threats of force than abuse by others, surpassing the "norm" for child sexual abuse. See Robin Fretwell Wilson, Children at Risk: The Sexual Exploitation of Female Children After Divorce, 86 Cornell L. Rev. 251, 274-77 (2001).

${ }^{179}$ Linda Williams \& David Finkelhor, Parental Caregiving and Incest: Test of a Biosocial Model, 65 Aм. J. OrThopsyCHIATRY 101, 102, 107 (1995) (comparing parental involvement for two groups of incestuous fathers, one recruited from the U.S. Navy and one recruited from civilian sources, with a closely matched group of control fathers).

${ }^{180} \mathrm{Id}$. at 109.

${ }^{181} I d$. at 111 .

${ }^{182} I d$. (noting that early involvement in non-bodily caretaking reinforces positive parenting skills and attitudes in fathers, creating nurturing parental responses).
} 
found to increase the risk of later [father-daughter] incestuous abuse." ${ }^{183}$ This is so because many incestuous fathers engage in high levels of caretaking as part of their efforts to "groom" the child. Intensive caretaking creates the conditions - time alone, unusual dependence, and the child's acceptance of intimate physical touch - that allow and encourage the child's tolerance of later sexual contact. ${ }^{184}$

In many ways, the presence of caretaking among the most bonded parents, and the least - those who seek to exploit a child sexually - is a lot like the classic antitrust problem in which two gas stations operate directly across from each other, charging the same price for gasoline. The fact of an identical price is consistent with either collusion or perfect competition. ${ }^{185}$ The problem is that price alone cannot tell us which of the two, collusion or competition, is operating. Likewise, the fact of caretaking does little to discern the adult's motivation and commitment to parenting. And unfortunately, the fate of a vulnerable child hangs in the balance.

Unlike many parents by estoppel, de facto parents do not believe that they were the child's biological father for a significant period of time after the child's birth. In the classic parent by estoppel case, the deceit serves the useful purpose of allowing the "parent" to bond with the child as if the child was his own biological child. Blossoming during this time are those mechanisms that dissuade most men from harming their "own." 186

\section{E. Continuing Contact Is Not an Unqualified Good to Children}

Clearly, the risk factors for child sexual abuse are complex and interlinked. Despite this complexity, what we do know is that coresidence with an unrelated male and separation from one or both biological parents matter greatly to a child's risk of sexual abuse. We also know that the inability to bond with a child at birth, or shortly thereafter, elevates a child's later risk of incest with the biological father or father-substitute. Finally, a mother's protective presence mitigates this risk.

Under the PrinCIPLES, not a single one of these mechanisms, which are known to protect a child from abuse, is necessarily present with de facto parents. An Ex Live-In Partner gains time with the child without the moderating presence of the child's mother; without the protection afforded by a biological or adoptive tie; without necessarily having bonded with the child at a young age; and without any guarantee that the adult is properly attached to the child and the child is attached to him. In short, the test for de facto parenthood brings none of these protective measures to bear on behalf of the children being laid claim to.

While the incest mechanism is complex and difficult to tease out, we do understand the long-term social, psychological, and economic effects of sexual abuse and exploitation to children. By advocating for rights that do not presently exist, the drafters are gambling with the lives of those children. The stakes are high. Sexual abuse at the hands of a parent

\footnotetext{
${ }^{183} I d$. at $103,108$.

${ }^{184}$ Id. at 110; see also John R. Christiansen \& Reed H. Blake, The Grooming Process in Father-Daughter Incest, in THE Incest Perpetrator: A Family Member No One Wants to Treat 88, 91-92 (Anne L. Horton et al. eds., 1990) (noting that pedophiles within the home use "boundary violations" - bathing, dressing, and bathroom behavior in "grooming" their daughters to participate in sexual activities, as acts of incest within the home overwhelmingly use coercion and not outright force).

${ }^{185}$ See Donald F. Turner, The Definition of Agreement Under the Sherman Act: Conscious Parallelism and Refusals to Deal, 75 Harv. L. Rev. 655, 659 (1962).

${ }^{186}$ Presumably, the benefits of this bonding carry forward even after the deceit is exposed.
} 
figure has devastating, corrosive effects on the child well into adulthood. ${ }^{187}$ The harsh consequences to child victims counsel against expanding parental rights without additional safeguards. ${ }^{188}$

\section{The ALI's Test for De Facto Parents Does Not Separate the Good Risks from the Bad}

Importantly, the test developed by the drafters to decide who counts as a de facto parent is poorly designed to exclude those individuals who pose the most significant risks. The very same conduct that would delight most women about their partner's interest in and interaction with her children, is also used to garner her trust and that of her child. Of the drafters' sixteen illustrative caretaking functions, eight overlap with and mirror those behaviors pedophiles engage in when "grooming" child victims, as Table 5.1 demonstrates. Child molesters read to children, child molesters bathe children, child molesters dress children, child molesters discipline children, child molesters shower children with attention and gifts.

Clearly, we are looking for the wrong things here, at least if we are concerned about mitigating the possibility of this risk for children. Instead of looking for time-in-residence as a proxy for the bonded, dependent relationship, the PrinCIPLES should look for that relationship itself. Admittedly, this inquiry would be less administrable, and involve greater cost, but it would more meaningfully respond to the risks this new entitlement poses for its intended beneficiaries.

Wisconsin allows a court to award visitation, but not custody, to individuals who formed "a relationship similar to a parent-child relationship[s] with [a] child." 189 In this formulation, what matters is whether the raison d'etre for awarding visitation is present: a bonded, dependent relationship that is parental in nature. Likewise, Oregon grants rights to "a person who establishes emotional ties creating child-parent relationship or ongoing personal relationship" with a child. ${ }^{190}$

\section{Can the ALI's Test Be Refined to Minimize Harms while Preserving the Goods?}

In any revised test for de facto parent, attachment should figure more prominently. If the child is improperly attached to the adult, then the benefits of continuing contact to the child will be small, and the risks will be high. Rather than using disproportionate attachment only as grounds for departure from the past caretaking standard, as the ALI does, attachment could be used to decide who has standing to seek time with the child after the adults'

187 See Joseph H. Beitchman et al., A Review of the Long-Term Effects of Child Sexual Abuse, 16 CHILd ABuse \& NegleCt 101 (1992) (describing the impact of child sexual abuse on its victims).

${ }^{188}$ Legal parents should retain the prerogative to decide who has unsupervised access to their children even when no indication of risk is present at break up. Even if the mother's ex-partner never previously touched the child, he may do so when the child is outside the mother's discerning view.

Handing out parental rights to an Ex Live-In Partner ties the mother's hands in important ways. Consider the mother who ends a relationship because she suspects her partner might abuse her child in the future and who, acting on this concern, subsequently denies him access. Prior to the onset of actual abuse, she probably could not substantiate her concerns and even if she could, the concern may not rise to the level of abuse, as defined in state law. Principles $\$ 2.03(7)$. But he could prove her denial of visitation, which could then be used against her under Section $2.11(1)(\mathrm{d})$, and ultimately give him even greater access to her child as a result.

189 Wis. Stat. Ann. \$767.245 (West 2001). $\quad 190$ Or. Rev. Stat. \$109.119 (2003). 
Table 5.1. ALI caretaking functions and grooming of child victims: a comparison

\begin{tabular}{|c|c|}
\hline ALI Caretaking Functions & Grooming Behaviors \\
\hline Grooming $^{1}$ & Bathing 3,4 \\
\hline Washing ${ }^{1}$ & Bathing ${ }^{3,4}$ \\
\hline Dressing $^{1}$ & Dressing $^{3,4}$ \\
\hline Toilet Training ${ }^{1}$ & Bathroom Behavior ${ }^{3}$ \\
\hline Playing with child ${ }^{1}$ & Attention ${ }^{2,3,6}$ Affection $^{2,6}$ \\
\hline Bedtime and Wakeup ${ }^{1}$ & Being around child at bedtime ${ }^{6}$ \\
\hline \multicolumn{2}{|l|}{ Satisfying Nutrition Needs ${ }^{1}$} \\
\hline \multicolumn{2}{|l|}{ Protecting child's safety ${ }^{1}$} \\
\hline \multicolumn{2}{|l|}{ Providing transportation ${ }^{1}$} \\
\hline \multicolumn{2}{|l|}{ Directing development ${ }^{1}$} \\
\hline Discipline $^{1}$ & Discipline $^{6}$ \\
\hline \multicolumn{2}{|l|}{ Arranging for education ${ }^{1}$} \\
\hline \multicolumn{2}{|l|}{ Helping to develop relations ${ }^{1}$} \\
\hline \multicolumn{2}{|l|}{ Arranging for health care ${ }^{1}$} \\
\hline Providing moral guidance ${ }^{1}$ & $\begin{array}{l}\text { Assure child of rightness; }{ }^{3} \text { telling child that acts would } \\
\text { not hurt them }{ }^{3}\end{array}$ \\
\hline \multicolumn{2}{|c|}{ Arranging alternate care for child ${ }^{1}$} \\
\hline & Bribes $^{2,3,5,6}$ \\
\hline & Trust $^{2,3,6}$ \\
\hline & Alienating child from peers and family $y^{3,6}$ \\
\hline & Secrecy $y^{3,4,6}$ \\
\hline & Sexually Explicit and Vulgar Conversation ${ }^{3,6}$ \\
\hline
\end{tabular}

Sources:

${ }^{1}$ Principles $\$ 2.03 \mathrm{cmt}$. g., at 125 .

2 David Finkelhor, Child Sexual Abuse: New Theory and Research (1984).

${ }^{3}$ John R. Christiansen \& Reed H. Blake, The Grooming Process in Father-Daughter Incest, in The INCEST Perpetrator: A Family Member No One Wants to Treat (Anne L. Horton et al. eds., 1990).

${ }^{4}$ Patricia Bell, Factors Contributing to a Mother's Ability to Recognise Incestuous Abuse of Her Child, 25 WoMEN's STUd. INT'L F. 347 (2002).

5 Jon R. Conte, The Nature of Sexual Offenses Against Children, in Clinical Approaches to Sex Offenders And Their Victims (Clive R. Hollin \& Kevin Howells eds., 1991).

${ }^{6}$ Jon R. Conte et al., What Sexual Offenders Tell Us About Prevention Strategies, 13 Child Abuse \& Neglect 293 (1989).

breakup. If used in this way, an Ex Live-In Partner would not have standing at all unless he was the psychological parent. This is the approach taken in V.C. v. M.J.B, in which the court concluded that the psychological parent of the child had standing to proceed in a custody case. ${ }^{191}$ The psychological parent-child bond arguably is a more effective sorting mechanism than time in residence as an equal caretaker. Including a "psychological parent" requirement would remove many men who pose risks, while perhaps allowing continuing contact only with those men with whom a child would benefit, on balance. However states choose to define de facto parents, it should "surely be limited to those adults who have fully and completely undertaken a permanent, unequivocal, committed, and responsible parental role in the child's life." ${ }^{\prime 92}$ These are the relationships that should be preserved and continued.

Alternatively, the Principles could give courts the discretion to allow nonparents to go forward when they deem it is in the best interests of the child, as occurs with

191748 A.2d 539 (N.J. 2000).

192 C.E.W. v. D.E.W., 845 A.2d 1146, 1152 (Me. 2004). 
intervention. ${ }^{193}$ At least this would be an individual-specific inquiry, rather than the conferral of possible rights wholesale on Ex Live-In Partners. Or, like the drafters' treatment of intervention by third parties in Section 2.04(2), de facto parents could be given the ability to intervene in pending actions, but not the right to initiate actions unilaterally.

The ALI's proposal raises not just a question of who counts. It also raises questions about what they should receive. The ALI's proposal ratchets up the "rights" of de facto parents, via the past caretaking standard, entitling them to as much as an equal share of custody since they performed equal caretaking. While a real 50/50 split is impracticable, the use of the past caretaking standard would permit courts to award Ex Live-In Partners much more unsupervised time than de facto parents presently receive in most states.

Obviously, one problem with any approach is underinclusiveness: removing too many good men from the tent of "de facto parenthood." Yet even these good men would have some recourse - they could file a complaint for custody under the traditional third-party custody standard, which generally requires exceptional circumstances or unfitness of the legal parent. ${ }^{194}$ Or they could secure a voluntary agreement after the breakup with the legal parent. ${ }^{195}$ With the latter, of course, the question becomes how many good men will be unable to secure an agreement with the child's mother. If the relationship between the child and the mother's ex-partner is good for the child, we can expect lots of mothers will want to preserve that relationship.

It is certainly true that many of the de facto parent cases are very sympathetic and raise claims that require a response, both out of fairness to the adult and out of concern for the child - for instance, those cases in which the de facto parent survives the child's legal parent and is willing to continue caring for a child after the death but is challenged in this by a biological father who has been largely absent or by a more distant relative. In this instance, a continuing relationship with the de facto parent may shield the child from even greater dislocation following the parent's death and may be a source of comfort and continuity. Moreover, the de facto parent and mother may have had a biological child in common, so that removing the mother's child from the de facto parent's care jeopardizes that child's relationship with his or her siblings. Indeed, the de facto parent may well represent the best adult available to care for this child. Preserving this relationship is very different, however, from providing continuing contact with a mother's ex-partner outside her supervision and over her veto, while carving into the time that she spends with the child. States are always free to address the claims of adults in only the most compelling cases, without diluting the value of these reforms by reaching cases in which it is far less clear how children will fare.

\section{Conclusion}

By sleight of hand, designating more and more adults as "parents" to whom custodial responsibility may be given, the ALI glosses over significant differences in the protective capacities of legal parents and other caretakers - as well as their desires to exploit children.

\footnotetext{
193 See Principles $\$ 2.04$, Reporter’s Notes, cmt. g, at 142 (noting that courts in some states "have considerable discretion to allow nonparents to intervene in custody disputes"); Id. $\$ 2.04 \mathrm{cmt}$. a, at 135 (allowing individuals to intervene whose participation, the court finds, "is likely to serve the child's best interests").

194 See generally Murphy, supra note 61.

${ }^{195}$ Principles $\$ 2.05 \mathrm{cmt}$. $\mathrm{f}$, at 150 (noting that separating adults are "free to settle any issues they wish on their own").
} 
The drafters see continuing contact between de facto parents and the children of their former partners as a good in itself, or a net good.

Only when we consider the evidence of possible harms to children do we realize how irresponsible it is - without sound evidence or additional safeguards - to cling to the ideal of "neutrality toward diverse lifestyles" 196 and to confer parent-like rights upon the adults involved. Some of these adults may well be good risks, as legal parents are. ${ }^{197}$ Others may not.

Obviously, concerns about sexual and physical abuse should not overwhelm other values. Nonetheless, the sorts of concerns raised here should be included in any cost-benefit analysis of promoting continuing contact between children and Ex Live-In Partners. Legislators should evaluate, for example, what portion of the adults who seek to continue their relationship with children do so for malign reasons, and what portion for benign ones. They should also ask how much better off some children would be, and weigh this against how much worse off others would become. Unfortunately, the ALI has not done this important work in the Principles for legislators and policymakers.

We have not had gleaming results thus far from our grand social experiment in redesigning the family. Now, arguably, we do not bear collective responsibility for those consequences we could never have anticipated. ${ }^{198}$ But we can and will be judged for putting into motion changes that we should reasonably expect will make some children worse off, and profoundly so. We should institute such reform only if we think the ALI has met its burden of proof-namely, that the gains far exceed the costs. ${ }^{199}$ The ALI has not convincingly demonstrated that extending parental rights to every Ex Live-In Partner who shares caretaking duties for a child for as little as two years would benefit children more than it harms them.

An earlier version of this chapter was presented at the October 2004 Workshop, "Critical Reflections on the American Law Institute's Principles of the Law of Family Dissolution," held at the Harvard Law School and to 12th World Conference of the International Society of Family Law. I am indebted to the Workshop and ISFL participants, to an anonymous outside reviewer, and to Jane Murphy, John Lopatka, and Pamela Melton for comments on an earlier draft, as well as to Michael Clisham for his diligent and cheerful research assistance.

${ }^{196}$ Glendon, supra note 6, at 3.

197 The drafters repeatedly pay homage to the ability of legal parents to safeguard children. For instance, they explain their use of parenting plans as "locat[ing] responsibility for the welfare of the child in the first instance in parents rather than in courts.” Principles $\$ 2.05 \mathrm{cmt}$. a, at 145 .

${ }^{198}$ For example, we presumably could not have discovered, ex ante, the link between the breakup of the parental relationship and instability in a child's own relationships as an adult. See, e.g., WALlERsteIN ET AL., supra note 6 (showing that children of divorced parents have marriages that dissolve at higher rates than children whose parents did not divorce).

${ }^{199}$ As the Maine Supreme Court said in Merchant v. Bussell, 27 A.2d 816, 818 (Me. 1942). "The natural right of a parent to the care and control of a child should be limited only for the most urgent reasons." 